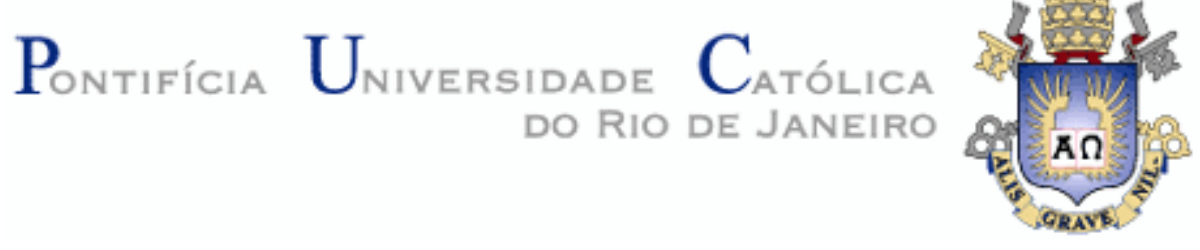

Joana Silva da Rocha

Redesenho de um Sistema de Medição de Desempenho: um framework e sua aplicação no setor de óleo e gás

Dissertação de Mestrado

Dissertação apresentada como requisito parcial para obtenção do grau de Mestre pelo Programa de Pósgraduação em Engenharia de Produção do Departamento de Engenharia Industrial da PUC-Rio.

Orientador: Prof. Luiz Felipe Roris Rodriguez Scavarda Do Carmo 


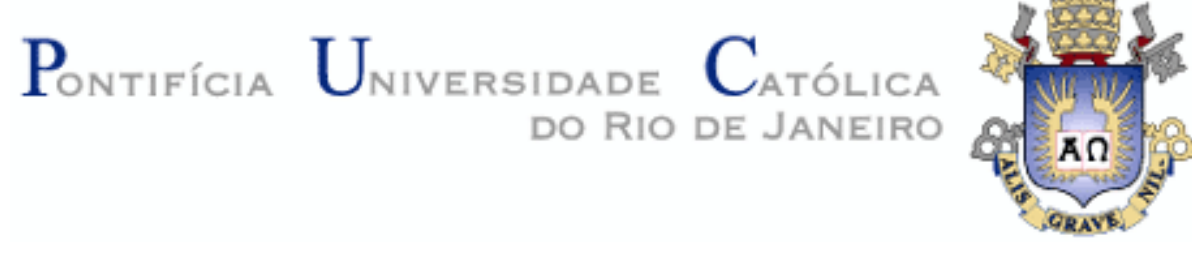

Joana Silva da Rocha

\section{Redesenho de um Sistema de Medição de Desempenho: um framework e sua aplicação no setor de óleo e gás}

Dissertação apresentada como requisito parcial para obtenção do grau de Mestre pelo Programa de Pós-graduação em Engenharia de Produção do Departamento de Engenharia Industrial da PUC-Rio. Aprovada pela Comissão Examinadora abaixo.

Prof. Luiz Felipe Roris Rodriguez Scavarda do Carmo Orientador

Departamento de Engenharia Industrial - PUC-Rio

Prof. Paula Santos Ceryno

UNIRIO

Prof. Rodrigo Goyannes Gusmão Caiado

Departamento de Engenharia Industrial - PUC-Rio 
Todos os direitos reservados. É proibida a reprodução total ou parcial do trabalho sem autorização da universidade, da autora e do orientador.

\section{Joana Silva da Rocha}

Graduou-se em Engenharia de Produção pela Universidade Federal Fluminense - UFF em 2012. Cursou Pós Graduação em Finanças pela IBMEC. Atua na área de Gestão de Estoques em empresa na área de Oleo e Gás.

Ficha Catalográfica

Rocha, Joana Silva da

Redesenho de um sistema de medição de desempenho : um framework e sua aplicação no setor de óleo e gás / Joana Silva da Rocha ; orientador: Luiz Felipe Roris Rodriguez Scavarda do Carmo. $-2019$.

67 f. ; $30 \mathrm{~cm}$

Dissertação (mestrado)-Pontifícia Universidade Católica do Rio de Janeiro, Departamento de Engenharia Industrial, 2019.

Inclui bibliografia

1. Engenharia Industrial - Teses. 2. Sistema de medição. 3. Revisão de SMD. 4. Etapa piloto. 5. Indicadores de desempenho. 6. Setor de óleo e gás. I. Carmo, Luiz Felipe Roris Rodriguez Scavarda do. II. Pontifícia Universidade Católica do Rio de Janeiro. Departamento de Engenharia Industrial. III. Título. 


\section{Agradecimentos}

Aos meus pais Cristian e Fabio, por todo incentivo e amor incondicional.

Ao meu orientador, Prof. Luiz Felipe Scavarda pela dedicação e paciência.

Aos meus familiares e amigos pela parceria de sempre.

Aos professores da comissão examinadora pela contribuição ao trabalho.

Agradeço ainda à CAPES e à PUC-Rio pelos auxílios concedido e a todos os funcionários do DEI pela ajuda e suporte.

O presente trabalho foi realizado com apoio da Coordenação de Aperfeiçoamento de Pessoal de Nível Superior - Brasil (CAPES) - Código de Financiamento 001. 


\section{Resumo}

Silva da Rocha, Joana; Roris Rodriguez Scavarda Do Carmo; Luiz Felipe (Orientador). Redesenho de um Sistema de Medição de Desempenho: um framework e sua aplicação no setor de óleo e gás. Rio de Janeiro, 2019. 67 p. Dissertação de Mestrado - Departamento de Engenharia Industrial, Pontifícia Universidade Católica do Rio de Janeiro.

Sistemas de Medição de Desempenho (SMD) são amplamente estudados por meio de trabalhos teóricos e práticos. No âmbito de trabalhos práticos, é identificado na literatura uma carência de estudos empíricos que englobem a etapa de implementação. Já os estudos que abordam tal etapa relatam diversas barreiras, o que corrobora com a necessidade de considerar a etapa piloto antes da implementação completa. Essa dissertação de mestrado tem como objetivo: propor um framework conceitual com diretrizes para o redesenho de SMD já existentes comtemplando formalmente uma etapa piloto e realizar o redesenho de um SMD através da utilização de um estudo empírico utilizando o framework conceitual proposto. Além redesenhar o processo e avaliar as barreiras enfrentadas em sua implantação, a dissertação fornece uma avaliação da forma com que a etapa piloto introduzida conseguiu mitigar os riscos mapeados na literatura.

\section{Palavras-chave}

Sistema de Medição; Revisão de SMD; Etapa Piloto; Indicadores de Desempenho; Setor de Óleo e Gás; Implementação. 


\section{Abstract}

Silva da Rocha, Joana; Roris Rodriguez Scavarda Do Carmo, Luiz Felipe (Advisor). Redesign of a Performance Measurement System: a framework and its application in the oil and gas sector. Rio de Janeiro, 2019. $67 \mathrm{p}$. Dissertação de Mestrado - Departamento de Engenharia Industrial, Pontifícia Universidade Católica do Rio de Janeiro.

Performance Measurement Systems (PMS) are extensively studied through theoretical and practical work. In the scope of practical work, a lack of empirical studies concerning the implementation stage is identified in the literature. The studies that approach this stage report several barriers, which corroborates with the need to consider the pilot stage before full implementation. This dissertation aims to: propose a conceptual framework with guidelines for the redesign of existing PMS by formally contemplating a pilot phase and carry out the redesign of an PMS through the use of an empirical study using the proposed conceptual framework. In addition to redesigning the process and evaluating the barriers faced in its implementation, the dissertation provides an evaluation of the way in which the pilot stage introduced managed to mitigate the risks mapped in the literature.

\section{Keywords}

Performance Measurement System; Review of PMS; Pilot Phase; Performance Indicators; Oil \& Gas Sector; Implementation. 


\section{Sumário}

1 Introdução 12

2 Fundamentação Teórica 15

2.1 Sistema de Medição de Desempenho - SMD 15

2.2 Redesenho de Sistemas de Medição de Desempenho - SMD 17

3 Metodologia de Pesquisa 22

4. Dimensão Teórica e Industrial $\quad 24$

4.1 Dimensão Teórica 24

4.2 Dimensão Industrial Prática $\quad 27$

5. Estudo de Caso 31

5.1 As Is $\quad 31$

$\begin{array}{ll}5.2 \mathrm{To} \mathrm{Be} & 37\end{array}$

$\begin{array}{ll}5.3 \text { Piloto } & 40\end{array}$

5.4 Road Map $\quad 53$

6. Conclusões $\quad 54$

7. Referências bibliográficas $\quad 57$ 


\section{Lista de Figuras}

FIGURA 1: Framework Conceitual Adaptado de Bourne et al. (2000) .....25 


\section{Lista de Tabelas}

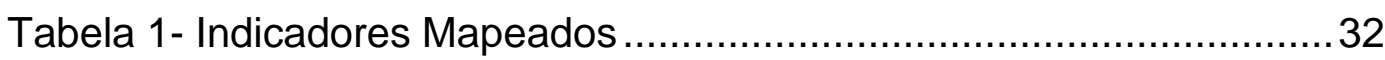

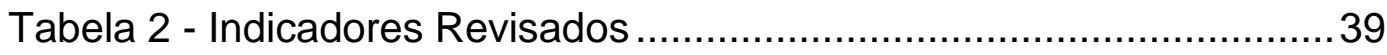

Tabela 3 - Barreiras Mapeadas e o Projeto Piloto .......................................51

Tabela 4 - Cronograma de Implementação (em meses) ...........................53 


\section{Glossário}

CMBPC - Continuous monitoring of business process controls

EVA - Economic Value Added

RFID - Radio-Frequency Identification

SMD - Sistema de Medição de Desempenho

TI - Tecnologia da Informação 


\section{Introdução}

O Sistema de Medição de Desempenho (SMD) ganhou destaque nos mundos acadêmico e corporativo e vem sendo usado amplamente pelos gestores com o intuito de auxiliar no processo de tomada de decisão (Braz et al., 2011). Segundo Kaplan e Norton (1996), eles têm como finalidade apoiar a implantação da estratégia nos vários níveis da organização. Os SMD incorporam um conjunto de métricas usadas para quantificar a eficácia e eficiência das ações (Neely et al., 1995). Processos, pessoas e sistemas de informação também fazem parte dos SMD (Braz et al., 2011). Nesse sentido, acadêmicos e profissionais da área estão interessados em entender como as organizações são mensuradas e a maneira pela qual é possível extrair valor das informações coletadas (Goshu et al., 2017).

Apesar de haver inúmeras discussões sobre os critérios e requisitos que os SMD devem possuir, não existe consenso em relação ao que é realmente suficiente e/ou necessário para sua elaboração, ilustrando apenas um dos desafios de realizar seu desenho (Goshu et al., 2017). Muitas organizações não são capazes de implementar totalmente os SMD ou não conseguem fazer com que o sistema funcione e obter os benefícios esperados da aplicação (Neely e Bourne, 2000; Franco-Santos e Bourne, 2005; Keathley e Van Aken, 2013; Bourne et al., 2018). Para obter sucesso na implementação de um SMD, o balanceamento entre a quantidade de indicadores e as informações necessárias para o monitoramento do processo e auxilio na tomada de decisão é fundamental (Fernandez et al., 2012).

Segundo Gutierrez et al. (2015), os estudos oferecidos pela literatura são, em sua grande maioria, relativos ao desenho de novos sistemas havendo carência de trabalhos focados em redesenho e implementação ou que abordem o ciclo de vida completo. É durante a fase de implementação, entretanto, que os principais problemas que podem gerar o insucesso no SMD são identificados (Van Camp e Braet, 2016). A etapa piloto aparece então como uma alternativa que pode contribuir na mitigação de problemas identificados na fase de implementação. Metodologicamente esta etapa é bem aceita na literatura acadêmica de Gerência da Produção, sendo utilizado em surveys (Forza, 2002) e estudos de caso (Voss et al., 
2010). O uso de pilotos também é comumente encontrado na literatura de tecnologia de informação (Alles et al., 2018).

Nesse contexto, esta dissertação de mestrado tem como objetivos (i) propor um framework conceitual com diretrizes para o redesenho de SMD já existentes contemplando formalmente uma etapa piloto, (ii) realizar o redesenho de um SMD através da utilização de um estudo empírico utilizando o framework conceitual proposto e apresentar achados e lições aprendidas.

Para definição de framework conceitual foi utilizada a proposta de Meredith (1993) que consiste em realizar a simplificação do fato ou abstração, mantendo a conexão com a realidade. $\mathrm{O}$ framework proposto apresenta elementos relevantes e proposições que descrevem o fenômeno (evento, realidade ou processo) (Meredith, 1993). A proposição do novo framework foi feita após mapeamento e verificação da adequação de frameworks já existentes na literatura e identificação de lacunas existentes. $O$ framework conceitual proposto apresenta boas práticas relativas ao redesenho e tem o objetivo de facilitar a implementação. A metodologia utilizada para o desenvolvimento do framework é a do "Discovery Oriented Approach" de Menon et al. (1999), que contempla três dimensões: teórica, industrial/prática e estudo de caso.

Em relação ao objetivo ii, foi realizada a análise e verificada a adequação do sistema atual. Na sequência, foram realizados o redesenho e a implantação do novo sistema. O estudo empírico será realizado em uma empresa do segmento de óleo e gás na área de Gestão de Estoques.

Esta dissertação está organizada em seis capítulos, sendo eles: Introdução, Fundamentação Teórica, Metodologia de Pesquisa, Dimensão Teórica e Industrial, Estudo de Caso e Conclusões. O primeiro capítulo consiste em uma introdução sobre o tema. O segundo capítulo oferece uma revisão teórica sobre SMD. O terceiro capítulo aborda a metodologia de pesquisa adotada. O quarto contempla as dimensões teórica e industrial do estudo, apresentando um framework para a revisão de SMD e o contexto da empresa na qual foi realizada o estudo. O quinto capítulo aborda o estudo de caso e discussões de resultados e o sexto e último 
capítulo oferece as conclusões abordadas pela autora e sugestões para pesquisas futuras.

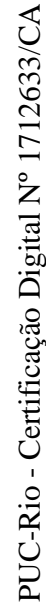




\section{2 \\ Fundamentação Teórica}

SMD possibilitam a melhoria da gestão nas organizações de negócio (Neely et al., 1995; Van Camp e Braet, 2016). Segundo Neely et al. (2005) e Vamp Camp (2016) houve crescimento significativo no volume de artigos publicados sobre o tema entre os anos 1990 a 2000 embora poucos focando nas lições aprendidas durante o processo de implantação (Van Camp e Braet, 2016). Esse capítulo oferece fundamentos de SMD com enfoque na fase de resenho que é o escopo desta dissertação.

\section{1}

\section{Sistema de Medição de Desempenho - SMD}

Segundo Neely et al. (1995), a medição de desempenho permite quantificar a eficiência e eficácia de ações. A medida de desempenho é uma métrica usada para quantificar ações passadas tornando possível a comparação com objetivos estabelecidos (Neely et al.,1995). Medir o desempenho de uma organização consiste em definir valores quantificáveis e classificáveis que possam, por exemplo, subsidiar a tomada decisão dos gestores (Fernandez et al., 2012). Nesse sentido, a utilização dos sistemas permite a tomada de decisão baseada em dados e não apenas na intuição dos gestores ou apenas com viés financeiro (Hourneaux et al., 2017).

Entretanto, os SMD não são mais limitados a gerar métricas e medir resultados, mas se concentram em gerenciar esses resultados. De acordo com Van Camp et Braet (2016), as principais causas de adotar um SMD são: planejar, monitorar, avaliar, controlar e comunicar atividades financeiras e operacionais; ajudar na tomada de decisão; maximizar o lucro através do aumento da rentabilidade; permitir alinhamento com as metas, objetivos e estratégia organizacional; recompensar e disciplinar colaboradores e liderança e fazer previsões em relação ao futuro. Nessa linha, Franco-Santos et al. (2007) ressaltam 
a necessidade de declarar de forma objetiva as condições que definem os SMD observando características, papéis e processos relacionados.

De acordo com Franco-Santos (2005) os SMD são, na verdade, uma sequência interdependente de eventos. Dado que o cenário em que uma organização está inserida é mutável, é importante pontuar que as medidas de desempenho precisam ser periodicamente revisadas para continuarem refletindo a realidade do negócio (Lynch e Cross, 1991; Braz et al., 2011).

Nesse contexto, apesar de fornecer informações de desempenho adequadas e analisar os resultados, o SMD deve ser revisado periodicamente com objetivo de manter o alinhamento com a estratégia (Nudurupati et al., 2011). Assim, deve ser estabelecida uma sistemática para revisar periodicamente todo o conjunto de medidas de acordo mudanças no ambiente competitivo e estratégia, incluindo mecanismos para rever indicadores e possibilitar a melhoria contínua (Gutierrez e al., 2015). De acordo com Neely et al. (1997), as métricas utilizadas para medição precisam ser transparentes, de fácil entendimento, possuir impacto visual, ter foco na melhoria do processo e ser acessível a todos os funcionários.

Apesar da sua reconhecida importância pelo meio acadêmico e organizacional, muitas implantações de SMD enfrentam dificuldades ou total insucesso no processo de implantação (Neely e Bourne, 2000; Franco-Santos e Bourne, 2005; Keathley e Van Aken, 2013; Bourne et al., 2018; Mendonça et al., 2019). Nesse sentido, a literatura focada na identificação de fatores críticos, tem ganhado destaque (Neely e Bourne, 2000; Bourne et al., 2003; Keathley e Van Aken, 2013; Mendonça et al., 2019). Ainda assim, de acordo com Van Camp e Braet (2016) a literatura falha ao não incorporar descrições e relatos de problemas reais encontrados no processo de implementação. Apenas um número bastante limitado de estudos aborda causas de fracasso ou se preocupa tal fato. 


\section{2}

\section{Redesenho de Sistemas de Medição de Desempenho - SMD}

SMD tradicionais foram desenvolvidos orientados ao acompanhamento de custos e sistemas contábeis (Hayes e Garvin, 1982). Com o intuito de proporcionar uma visão mais balanceada dos processos Keegan et al. (1989) propõe um framework que leva em consideração além dos processos internos, os externos, englobando as visões financeira e não financeira. Outro framework amplamente conhecido na literatura é de Kaplan e Norton (1996) que aborda as quatro perspectivas do Balanced Scorecard, sendo elas, financeira, clientes, processos internos/aprendizado e crescimento.

Com o passar do tempo, começaram a ser desenvolvidos ainda frameworks de sistemas que não estavam apenas focados em medir o desempenho, mas eram orientados a necessidades de gestão. Um dos desafios desta área de pesquisa é fornecer sistemas que incluam a gestão do desempenho e não apenas a medição (Neely, 2005). A maioria dos estudos encontrados na literatura está focado no desenho de novos sistemas, sendo poucos orientados a análise da implementação e atualização contínua dos sistemas (Borne et al.,2000; Gutierrez et al., 2015; Van Camp e Braet, 2016).

Tratando da etapa do redesenho, interessantes propostas foram apresentadas como a de Dixon et al. (1990) que propõe a utilização de questionários para identificar pontos fortes e fraquezas nos SMD atuais e workshops para realizar tal redesenho. Kaplan e Norton (1996) propõe a realização de entrevistas com membros da alta administração. Segundo Bourne et al. (2000), os frameworks existentes orientados a revisão de SMD focam, em sua grande maioria, em responder a questionamentos relativos a quais os tipos de medição uma empresa deve adotar, mas não proporcionaram um guia detalhado de como realizar sua implementação.

A sistemática proposta por Bourne et al. (2000) aborda de forma mais concisa a etapa da implementação. $\mathrm{O}$ framework está divido em três etapas: projeto, implementação e uso/revisão. A fase inicial consiste na identificação dos principais objetivos e contempla a concepção dos indicadores. Nessa etapa é necessário 
desenvolver uma sistemática para definir o conjunto final de métricas. Essas medidas devem ser estabelecidas com base na estratégia e considerando os clientes e requisitos das partes interessadas (Bourne e al., 2000). A fase de implementação consiste em alinhar sistemas e procedimentos, garantindo que as medições sejam feitas com regularidade conforme o desenho proposto (Bourne e al., 2000). A implementação efetiva requer o alinhamento da estrutura e sistemas organizacionais, sendo uma fase do trabalho que envolve custos adicionais com desenvolvimentos de, por exemplo, sistemas. A última fase do sistema, antes do início do ciclo de revisão, consiste na fase de uso. Nessa etapa é importante atualizar e melhorar o SMD (Bourne e al., 2000).

De acordo com Goshu e Kitaw (2017), a literatura referente a SMD ainda não possui consenso em relação a quais são as condições necessárias e suficientes para que um sistema obtenha sucesso ou ainda quais os fatores que devem suportar sua elaboração. Com isso, a etapa de Uso/Revisão é relevante já que o aprimoramento dos sistemas está baseado no processo de tentativa, erro e readequação. De acordo com Van Camp e Braet (2016), a literatura tem falhado ao não incorporar na melhoria dos frameworks propostos falhas encontradas durante a implantação em sistemas reais.

De acordo com Van Camp e Braet (2016), as causas de insucesso de SMD podem ser divididas em três níveis. O primeiro nível contempla as dificuldades na definição das métricas, indicadores e parâmetros. O segundo nível está relacionado ao processo de medição, sem considerar as métricas propriamente ditas. $\mathrm{O}$ terceiro e último nível contempla as causas de insucesso relativas ao processos de implementação, suporte e tomada de decisão envolvendo a equipe gerencial.

Após recorte de revisão bibliográfica realizada por Van Camp e Braet (2016) foram mapeados catorze motivos que podem levar ao insucesso do processo desenho e implementação de um SMD, sendo eles:

1. Falta de envolvimento gerencial - Conservadorismo, falta de interesse ou tempo para dedicar a iniciativa, assim como ações de resistência a mudança (Schneiderman, 1999; Bourne et al., 2000, 2002; Kennerley e Neely, 2002; Smith e Goddard, 2002; Scozzi et al., 2005; Garengo et al., 2005; Garengo e Bititci, 2007; Spitzer, 2007; De Waal e Counet, 2009; Nudurupati et al., 2011; Kellen, 2003; Van Camp e Braet 2016); 
2. Falta de alinhamento com a estratégia - Desalinhamento com outras metas da companhia e com a estratégia de longo prazo (Eccles, 1991; Neely, 1999; Schneiderman, 1999; Bourne et al., 2000, 2002; Kellen, 2003; Garengo et al., 2005; Spitzer, 2007; Van Camp e Braet 2016);

3. Falta de procedimento formal - Ausência de documentação e definições formais do processo que dificultam comunicação e definição de responsabilidade (Pawar e Driva, 1999; Schneiderman, 1999; Neely et al., 2000; Bourne et al., 2002; Kellen, 2003; Bird et al., 2005; Scozzi et al., 2005; Garengo e Bititci, 2007; Van Camp e Braet 2016);

4. Frequência insuficiente - A atualização das métricas com alta frequência pode gerar sobrecarga dos envolvidos na atividade, enquanto a falta de atualização pode fazer da métrica inútil ou defasada com a realidade (Suwignjo et al., 2000; Kennerley e Neely, 2002; Bird et al., 2005; Spitzer, 2007; Cedergren et al., 2010; Hope, 2011; Van Camp e Braet 2016);

5. Falta de sistema de recompensa - A ausência de um sistema de recompensa adequado pode gerar desinteresse pelo processo enquanto recompensas inadequadas podem gerar efeitos indesejados (Hauser e Katz, 1998; Smith e Goddard, 2002; Turban et al., 2011; Van Camp e Braet 2016);

6. Falta de suporte financeiro - O processo pode necessitar de gastos adicionais com sistemas, terceirizações, hardware, software, entre outros (Bierbusse e Seisfeld, 1997; Bourne et al., 2002; Garengo et al., 2005; Scozzi et al., 2005; Garengo e Bititci, 2007; Turban et al., 2011; Van Camp e Braet 2016);

7. Falta de capital humano - A ausência das habilidades necessárias para desempenhar as atividades, ou a restrição da quantidade de colaboradores pode trazer impactos na implantação (Pawar e Driva, 1999; Neely et al., 2000; Kennerley e Neely, 2002; Kellen, 2003; Davenport e Harris, 2005; Scozzi et al., 2005; Turban et al., 2011; Van Camp e Braet 2016);

8. Falta de suporte da TI - Suporte de TI inadequado pode dificultar a implementação como: integração com sistemas existentes; custos elevados; garantia da qualidade dos dados, dentre outros (Cooper, 1985; Bierbusse e Seisfeld, 1997; Pawar e Driva, 1999; Schneiderman, 1999; Neely e Bourne, 2000; Suwignjo et al., 2000; Kuczmarski, 2001; Bourne et al., 2000, 2002; 
Kellen, 2003; Nudurupati et al., 2011; Gutierrez et al., 2015; Van Camp e Braet 2016);

9. Falta de envolvimento do usuário - A falta de envolvimento e/ou consulta aos usuários no desenho e implementação pode gerar modelos complicados, métricas difíceis de medir e falta de interesse/ comprometimento (Kaplan e Norton, 2000; Suwignjo et al., 2000; Holloway, 2001; Kellen, 2003; Bird et al., 2005; Van Camp e Braet 2016);

10. Obstáculos Culturais - Resistência a mudança, atitudes negativas e conservadoras, falta de vontade/ engajamento (Pawar e Driva, 1999; Bourne et al., 2000; Neely et al., 2000; Holloway, 2001; Kennerley e Neely, 2002; Nudurupati et al., 2011; Van Camp e Braet 2016);

11. Falta de ações reativas/ pró ativas - Falta de ações reativas e pró ativas após análise do desempenho do SMD (Brouthers, 1998; Pawar e Driva, 1999; Kennerley e Neely, 2002; Smith e Goddard, 2002; Kellen, 2003; Scozzi et al., 2005; Garengo et al., 2005; Andrew et al., 2008; Nudurupati et al., 2011; Van Camp e Braet 2016);

12. Número elevado de stakeholders - O elevado número de partes interessadas/envolvidas pode dificultar o processo de tomada de decisão e ao consenso entre as partes (Cooper, 1985; Holloway, 2001; Kennerley e Neely, 2002; Smith e Goddard, 2002; Scozzi et al., 2005; Franco-Santos et al., 2007; Cedergren et al., 2010; Neely, 1999, 2011; Van Camp e Braet 2016);

13. Decisões tomadas pelo grupo em detrimento a decisões baseadas na análise dos dados - Tomada de decisão subjetiva ao invés de decisões baseadas em métricas e resultados (Schneiderman, 1999; Lazzarotti et al., 2011; Turban et al., 2011; Van Camp e Braet 2016);

14. Pressão em relação ao tempo - Construir e manter um SMD atualizado requer tempo de desenvolvimento e acompanhamento. A flexibilidade do SMD também é importante para manter a organizações atualizada quanto a inovações e mudanças de cenário da organização (Neely, 1998; Kaplan e Norton, 2000; Kellen, 2003; Spitzer, 2007; Chen et al., 2010; Lazzarotti et al., 2011; Van Camp e Braet 2016); 
As dificuldades mapeadas, comuns a fase de implementação, tendem a aumentar o tempo da atividade e dificultar a geração de resultados de curto prazo (De Waal e Counet, 2009). 


\section{3 \\ Metodologia de Pesquisa}

A metodologia utilizada para o desenvolvimento do framework é a do "Discovery Oriented Approach" de Menon et al. (1999), que contempla três dimensões: teórica, industrial/prática e estudo de caso.

A visão teórica tem como objetivo avaliar os conceitos de SMD já disponíveis na literatura com o intuito de conhecer o desenvolvimento da pesquisa relativa ao tema a ser estudado. A análise da literatura busca ainda identificar lacunas que podem gerar pesquisas futuras (Cauchick, 2007). A revisão da literatura foi realizada conforme proposta por Cauchick (2007), ou seja, de forma não sistemática. Nessa etapa, foram mapeados os principais conceitos relativos ao tema, estudos, frameworks, dificuldades enfrentadas durante a implantação/ revisão de SMD e como a inclusão da etapa piloto pode auxiliar no processo de implantações.

A dimensão industrial/prática tem como objetivo compreender o problema através de entrevistas, observação direta e da interação com profissionais da indústria. Nesta fase foram realizadas reuniões com especialistas de uma empresa brasileira do setor de óleo e gás com o objetivo de avaliar a aderência do framework proposto com a realidade empresarial. Foram entrevistados onze colaboradores envolvidos no processo que já participaram de desenho e/ou implementação de SMD na empresa. As entrevistas foram realizadas com perguntas abertas na linha de "brainstorming" tendo como objetivo auxiliar na elaboração da sequência de passos de uma revisão de um SMD. Foi solicitado aos profissionais entrevistados avaliar se a inclusão da etapa piloto no processo de redesenho poderia auxiliar na mitigação dos problemas enfrentados durante a fase de implementação e qual seria a melhor forma desta ser conduzida.

A terceira dimensão consiste na associação e análise das duas dimensões anteriormente estudadas que contou com a realização de um estudo de caso na empresa na indústria de óleo e gás envolvendo a aplicação de framework para rever o SMD que mede o desempenho da área de Gestão de Estoques. A inclusão da fase de Piloto na etapa de implementação tem como objetivo mitigar problemas 
identificados na literatura na etapa de implementação e ratificados na segunda dimensão através da entrevista com os profissionais. Durante a etapa piloto os indicadores foram testados e avaliados em um horizonte curto, de forma a avaliar a efetividade das medições propostas. O teste foi realizado num escopo reduzido dentro de uma organização, dentro de uma área específica, de forma a restringir o esforço empregado. A terceira dimensão conta com entrevistas apoiadas em um questionário semiestruturado. O questionário foi aplicado em 11 profissionais da empresa estudada. O formulário aplicado de entrevistas semiestruturadas pode ser consultado no Apêndice desta dissertação, enquanto que o protocolo de entrevistas resultante contou com as seguintes etapas (Bourne et al., 2002):

i. Nivelar definição do sistema de medição de desempenho;

ii. Levantar questões pré-estabelecidas;

iii. Validar respostas para garantir que o entrevistador entendeu os pontos abordados;

iv. Levantar questões focadas em uma lista rápida de possíveis fatores;

v. Validar respostas para garantir a compreensão;

vi. Após a entrevista, enviar o questionário para cada entrevistado para validação.

O principal objetivo do questionário é mapear o sistema atual e captar percepções, identificando oportunidades de melhoria. A tabulação dos dados visou identificar percepções similares.

A análise das evidências para o estudo de caso foi feita a partir da triangulação das informações coletadas durante as entrevistas. Para realização da triangulação foram utilizados: documentos internos da empresa, dados dos sistemas de informação da empresa e de observações diretas dos pesquisadores. A triangulação é fundamental para evitar o viés de pesquisa que se poderia obter ao se concentrar em apenas uma fonte (Yin, 2001). Na dissertação em questão a triangulação foi feita através da análise de padrões referentes ao processo, levantamento e análise de dados históricos e observação direta do pesquisador, que trabalha a seis anos na área. 


\section{4. \\ Dimensão Teórica e Industrial}

O capítulo 4 tem como objetivo abordar as dimensões teórica e prática do estudo de caso e apresentar o framework adaptado aplicado no estudo de caso. São apresentadas ainda informações sobre a empresa em que o estudo de caso foi aplicado.

\section{1}

\section{Dimensão Teórica}

A dimensão teórica tem o objetivo de propor a adaptação do framework para implantação/revisão de SMD visando mitigar as barreiras mapeadas na literatura. Para isso foi proposta a inclusão da etapa piloto. Parte desses resultados foram apresentados em Rocha et al. (2020).

\subsection{1}

\section{Barreiras a Utilização de Sistemas de Medição de Desempenho}

Segundo Goshu e Kitaw (2017) o sucesso de um SMD está atrelado as seguintes características: simplicidade, balanceamento, acuracidade, quantidade adequada de indicadores (poucos, mas suficientes) e custo.

Segundo Bourne et al. (2000), apesar de serem encontradas na literatura histórias de sucesso referentes a utilização de SMD, existem diversas dificuldades em realizar a implementação, o que faz com que $70 \%$ das iniciativas falhem.

De acordo com Van Camp e Braet (2016), a literatura tem falhado ao não incorporar nos frameworks propostos falhas encontradas durante a implantação em sistemas reais. No Capítulo 2 foram apresentados catorze motivos que podem levar ao insucesso de SMDs. 


\subsection{2 \\ A Etapa Piloto}

Após a etapa de projeto na qual é realizada o desenho de um novo sistema, a etapa de implementação aparece como o próximo desafio (Braz et al., 2011). É nesse momento que os principais problemas que podem gerar o insucesso do processo de revisão/ implementação de SMD são identificados (Van Camp e Braet, 2016).

Visando reduzir as barreiras identificadas na fase de implementação é proposto um framework contemplando quatro passos: (1) Projeto; (2) Piloto; (3) Implementação; (4) Revisão. A Figura 1 apresenta o framework para a revisão de um SMD. O framework proposto é uma adaptação de Bourne et al. (2000) que contempla três etapas: projeto, implementação e uso/revisão.

FIGURA 1: Framework Conceitual Adaptado de Bourne et al. (2000)

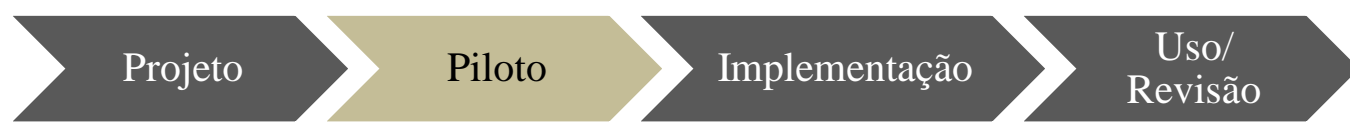

Fonte: Autora

A etapa piloto aparece como uma alternativa que visa contribuir na mitigação de problemas identificados na fase de implementação. Metodologicamente esta etapa é bem aceita na literatura acadêmica de Gerência da Produção, sendo utilizada em surveys (Forza, 2002) e estudos de caso (Voss et al., 2010). O uso de pilotos é ainda mais comum na literatura de tecnologia de informação (Fosso et al., 2010; Ruiz-Garcia et al., 2010; Liu et al., 2016; Alles et al., 2018).

Nesse sentido, foram identificados na literatura estudos que preveem a utilização da etapa piloto. O estudo proposto por Alles et al. (2018) aborda a implementação de uma camada de monitoramento para controle de processos de negócios (CMBPC) no departamento de auditoria de TI da Siemens Corporation, nos Estados Unidos. O departamento foi escolhido como um projeto piloto, de forma a ser possível avaliar de forma mais realista se os ganhos esperados seriam alcançados, ou seja, se o projeto teria o sucesso e retorno financeiro estimados na 
teoria. Nesse cenário, a etapa piloto foi utilizada para: determinar o melhor modo para desenvolver o controle contínuo; desenvolver a arquitetura para o sistema; identificar o melhor modo de realizar a integração entre os sistemas; desenvolver guias; criar processos para gerenciamento dos alarmes emitidos no monitoramento e formular um plano de gerenciamento de mudanças para mover o projeto do estágio de piloto para escala industrial (Alles et al., 2018). Ainda na área de TI o estudo realizado por Fosso et al. (2010) contempla a etapa piloto com o escopo de implementar a tecnologia de RFID na área de armazenagem, com o intuito de melhorar os controles internos do armazém.

$\mathrm{Na}$ área da logística, também foram encontrados projetos que incluem a etapa piloto. Devido a descentralização do suprimento em muitas regiões e agências, a China vem enfrentando graves problemas relativos a segurança alimentar, tornando necessário o monitoramento (Liu et al., 2016). O estudo proposto por Liu et al. (2016) propõe a utilização de uma etapa piloto para validar a utilização de Internet das Coisas ("The Internet of things") para facilitar o rastreamento do processo do fornecimento de alimentos na China. Apesar do projeto ter como escopo a área da logística, este possui alta natureza tecnológica necessitanto testar a tecnologia utilizada. O estudo realizado por Ruiz-Garcia et al. (2010) de forma similar a Liu et al. (2010) utiliza um protótipo para teste de tecnologia que tem como objetivo rastrear alimentos ao longo da cadeia, ou seja, desde a produção agrícola até a chegada nos consumidores.

$\mathrm{Na}$ área da gerência da produção, o estudo proposto por Erik Eriksson (2010), propõe a utilização de um projeto piloto em um estudo de caso voltado para a implantação de um sistema de produção enxuto na fábrica da empresa Scania, fabricante de veículos pesados como ônibus e caminhões, e sua subsidiária DynaMate. Segundo Erik Eriksson (2010), a etapa piloto serve como ponto de partida para implementação de melhorias e possibilita o desenvolvimento de projetos futuros, já que reduz o valor inicial investido e permite analisar de forma mais realista se o esforço e custos envolvidos são compensados pelos benefícios gerados.

Para literatura de SMD o uso de pilotos é relatado, mas sem grande enfoque. Braz et al. (2011) fez uso de um piloto para testar um protótipo para 
resenho de SMD. De acordo com Mendonça et al. (2019), o uso de um protótipo da ferramenta de análise dos indicadores auxilia nos testes e dá suporte às exigências de TI, possibilitando ter os dados arrumados e certeza das fontes de informação. Nesse sentido, o uso de um protótipo facilita o processo de validação / revisão das métricas e fontes de informação (Lohman et al., 2004; Braz et al., 2011; Fernandez et al., 2012). Entretanto, pode ser percebido que a literatura de SMD não oferece um guia de como desenhar e conduzir um estudo piloto.

\section{2}

\section{Dimensão Industrial Prática}

A empresa selecionada para desenvolvimento do trabalho atua no Brasil no setor de óleo e gás, sendo classificada como de grande porte. Com relação ao setor escolhido para realizar o estudo, o setor de petróleo é um importante fornecedor de energia para o mundo. Atualmente cerca de 52,5\% da energia primária mundial é suprida por petróleo e gás natural, e de acordo com estudos do setor, continuará a ser relevante no longo prazo com estimativas que sinalizam que o setor de petróleo e gás permanecerá suprindo uma parte significativa (50\% em 2040) da necessidade de energia do mundo (Instituto Brasileiro de Petróleo Gás e Biocombustíveis, 2017).

A companhia em que o estudo foi desenvolvido possui atuação nos segmentos de exploração, produção, refino, comercialização, transporte e distribuição de petróleo, derivados e gás natural. A empresa atua ainda nos segmentos de energia elétrica, biocombustíveis e petroquímicos. As duas principais áreas operacionais da empresa estão divididas entre a diretoria de Exploração e Produção, que compreende as investigações preliminares das reservas de petróleo e gás natural, perfuração, exploração e produção de petróleo, e a diretoria de Refino e Gás Natural, responsável por atividades que vão desde operações de alívio de plataformas, passando pelos processos de refino de petróleo e processamento de gás natural, até as atividades de comercialização e entrega de petróleo, gás natural e seus derivados.

Devido a mudanças no cenário interno e externo como redução do preço de referência do barril de petróleo, alta do dólar, investimentos com baixo retorno, 
e cancelamento de projetos, dentre outros, a empresa foi inserida num cenário fortemente orientado a redução de custos e otimizações. Nesse contexto, o estoque foi identificado com um forte potencial de contribuição devido a possibilidade de reduzir custos com a aquisição novos materiais (através da utilização dos materiais já em estoque) e gastos com estoque e armazenagem.

Nesse cenário, a área escolhida para revisão do sistema atual é a de Gestão de Estoques. O principal desafio da área consiste em gerir o elevado capital alocado a estoque. O objetivo da área é garantir o nível de serviço das operações utilizando a menor quantidade possível de estoques. Nesse sentido, é importante identificar itens sem previsão de uso, fomentar a utilização de itens alternativos e minimizar custos relativos a atividade. O direcionador de redução de custo, entretanto, é sobreposto pelo de nível de serviço. A continuidade das operações é imprescindível. O custo de falta de um item é elevado devido a possibilidade de interrupção da operação, que possui alta margem.

O estoque é divido em três principais grupos, sendo eles: itens de reposição automática, itens estratégicos e itens comprados para demanda específica (usualmente para projetos). A gestão dos itens de reposição automática é de responsabilidade da área de Suprimentos e tem como objetivo garantir que as compras de itens de consumo rotineiro sejam realizadas da forma mais econômica possível considerando os custos de compra, estocagem, armazenagem e lead time. São, de forma geral, itens de baixo valor e consumo rotineiro. Os itens estratégicos são parametrizados pelas Unidades e consistem em materiais como sobressalentes, que possuem baixo consumo, mas que em situações de emergência são imprescindíveis. Esses itens são vinculados a listas técnicas de equipamentos. Por fim, temos os itens comprados para demandas específicas como projetos ou manutenções de escopo definido. Tais itens possuem, de forma geral, alto lead time de fabricação e valor agregado.

A gerência objeto do estudo teve sua atividade centralizada no segundo semestre de 2018, sendo antes formada por quatro áreas distintas que atendiam segmentos de negócio diferentes. Cada gerência possuía seu próprio SMD, existindo similaridades e diferenças entre eles. Nesse sentido, foi essencial padronizar os sistemas, permitindo uniformidade na forma de gestão, mas garantindo que as particularidades fossem contempladas. 
A etapa de entrevistas foi realizada com onze profissionais: cinco da área de Gestão de Estoques e seis das áreas usuárias de interface. Foram selecionados para as entrevistas profissionais com envolvimento no processo e que poderiam contribuir criticamente com o processo.

Durante a etapa de entrevistas, foi pontuada a dificuldade de implementar um SMD. Foram levantados fatores como a dificuldade em definir o número ideal de indicadores tendo em vista a capacidade de traduzir a realidade dos processos e a viabilidade de realizar o acompanhamento, em termos de quantidade de métricas usadas. Ou seja, os indicadores precisam espelhar a realidade, mas o excesso de métricas pode ser um dificultador.

Com relação aos dados a serem analisados, foi pontuado que o esforço com a "precisão de medição", em muitos casos, acaba prejudicando o desenho do novo processo e a posterior implementação. Outro ponto destacado foi a necessidade de alinhar as métricas de medição com referências externas da indústria, ou seja, trabalhar com benchmark externo a empresa.

Com relação a padronização, foi destacada a necessidade de uniformizar a métrica de medição, de modo que seja possível comparar as áreas e ter os dados disponíveis com a periodicidade adequada para facilitar a tomada de decisão. Outra questão destacada foi o acompanhamento do plano de ação. No modelo de governança utilizado antes da revisão, cada área que não tivesse alcançado a meta do indicador estoque total deveria elaborar um plano de ação. O plano de ação apresentado pelas áreas, entretanto, nem sempre refletia ações efetivas ou refletia ações que acabavam não sendo acompanhadas.

Os profissionais foram questionados quanto a inclusão de uma etapa piloto precedendo a fase de implementação. A etapa foi vista de forma positiva. Foram pontuados projetos anteriores que após longo tempo de desenvolvimento pela equipe de TI, os painéis de acompanhamento se mostraram desconexos com a realidade da empresa. Ou seja, embora o desenvolvimento de uma ferramenta pela TI torne o processo de extração de dados mais ágil, permitindo acompanhamento em períodos menores, ou até em tempo real, uma vez definidas, as métricas ficam “engessados", ou seja, perde-se a flexibilidade de realizar ajustes. A flexibilidade é grande quando se utiliza, por exemplo, uma planilha Excel. Nesse sentido, é importante ter certeza que as métricas propostas são adequadas para a realidade da empresa no cenário atual, mesmo que, no futuro, sejam necessárias revisões. 
A inclusão da etapa piloto foi avaliada como uma possibilidade de mitigar as causas de fracasso comuns durante o processo de implementação. Nesse sentindo, os profissionais entrevistados entendem que a inclusão da fase pode mitigar riscos mapeados, principalmente por possibilitar maior flexibilidade e adaptações.

A expectativa dos profissionais com a implementação do novo sistema é que este facilite a tomada de decisão, torne possível comparar o desempenho das diferentes áreas de forma, evidencie pontos que necessitam de melhoria e práticas de sucesso que possam ser replicadas. É esperado ainda que o plano de ação elaborado com base nas análises realizadas reflita ações que possam gerar benefícios efetivos. 


\section{5. \\ Estudo de Caso}

O presente capítulo apresenta o estudo de caso em que o framework para revisão do SMD foi aplicado. São apresentados o processo: as is, predecessor a revisão proposta, o novo processo to be e os achados durante o estudo.

\section{1}

As Is

Para mapear os processos "as is", foram realizadas entrevistas suportadas por um questionário semiestruturado com 11 profissionais envolvidos no tema. $\mathrm{O}$ questionário está disponível no Apêndice desta dissertação. Essa etapa permitiu mapear como funcionavam os sistemas existentes e quais eram as expectativas e oportunidades de melhoria que os envolvidos percebiam.

Todas as áreas possuíam periodicidade mensal de acompanhamento, apesar de uma área extrair os dados semanalmente para análise e verificações interna. As reuniões de acompanhamento possuíam diferente periodicidade e perfil de participação. Algumas envolviam gerentes e coordenadores e outras apenas membros da equipe. Uma das áreas indicou não realizar nenhuma reunião presencial com a Unidade Operacional relativa.

$\mathrm{Na}$ etapa de mapeamento, foram identificados os indicadores acompanhados por cada uma das áreas. A Tabela 1 apresenta os indicadores mapeados. As colunas contemplam (nesta ordem): nome do indicador, unidade de medida, objetivo que pretende ser medido com o indicador, se o indicador possuía meta ou não e, por último, a quantidade de áreas que faziam uso do indicador, podendo variar de 1 a 4. 
TABELA 1: Indicadores Mapeados

\begin{tabular}{|c|c|c|c|c|c|c|}
\hline \multicolumn{2}{|c|}{ Indicador } & \multirow{2}{*}{$\begin{array}{l}\text { Unidade } \\
\text { de Medida } \\
\mathrm{R} \$\end{array}$} & \multirow{2}{*}{$\begin{array}{l}\text { Tipo } \\
\text { Custo }\end{array}$} & \multirow{2}{*}{$\begin{array}{l}\text { Métrica } \\
\sum \text { Valor dos itens em estoque }\end{array}$} & \multirow{2}{*}{$\begin{array}{l}\text { Possuía } \\
\text { meta? } \\
\text { Sim }\end{array}$} & \multirow{2}{*}{$\begin{array}{l}\text { Áreas que já utilizam o } \\
\text { indicador (0 a } 4 \text { áreas) } \\
4 \text { áreas }\end{array}$} \\
\hline 1. & Estoque Total & & & & & \\
\hline 2. & $\begin{array}{l}\text { Estoque de } \\
\text { Operação }\end{array}$ & $\mathrm{R} \$$ & Custo & $\sum$ Valor dos itens em estoque de operação & Não & 2 áreas \\
\hline 3. & $\begin{array}{l}\text { Estoque de } \\
\text { Investimento }\end{array}$ & $\mathrm{R} \$$ & Custo & $\sum$ Valor dos itens em estoque de investimento & Não & 2 áreas \\
\hline 4. & $\begin{array}{l}\text { Estoque sem } \\
\text { consumo há } 24 \\
\text { meses }\end{array}$ & $\mathrm{R} \$$ & Custo & $\begin{array}{l}\sum \text { Valor dos itens em estoque sem consumo a } \\
24 \text { meses }\end{array}$ & Não & 2 áreas \\
\hline 5. & $\begin{array}{l}\text { Estoque } \\
\text { destinado a } \\
\text { Alienação }\end{array}$ & $\mathrm{R} \$$ & Custo & $\begin{array}{l}\sum \text { Valor dos itens em estoque em depósito } \\
\text { específico de alienação }\end{array}$ & Não & 4 áreas \\
\hline 6. & $\begin{array}{l}\text { Estoque sem } \\
\text { previsão de } \\
\text { consumo }\end{array}$ & $\mathrm{R} \$$ & Custo & $\begin{array}{l}\sum \text { Valor dos itens em estoque sem previsão de } \\
\text { consumo }\end{array}$ & Não & 2 áreas \\
\hline
\end{tabular}




\begin{tabular}{|c|c|c|c|c|c|c|}
\hline 7. & $\begin{array}{l}\text { Compras } \\
\text { recebidas de } \\
\text { materiais para } \\
\text { estoque }\end{array}$ & $\mathrm{R} \$$ & Custo & $\sum$ Valor das compras por estoque no mês & Não & 4 áreas \\
\hline 8. & $\begin{array}{l}\text { Consumo de } \\
\text { materiais para } \\
\text { estoque }\end{array}$ & $\mathrm{R} \$$ & Custo & $\sum$ Valor do consumo por estoque no mês & Não & 4 áreas \\
\hline 9. & $\begin{array}{l}\text { Devolução de } \\
\text { materiais para } \\
\text { estoque }\end{array}$ & $\mathrm{R} \$$ & Custo & $\begin{array}{l}\sum \text { Valor da devolução dos materiais para } \\
\text { estoque }\end{array}$ & Não & 4 áreas \\
\hline 10. & $\begin{array}{l}\text { Baixa por } \\
\text { alienação de } \\
\text { materiais para } \\
\text { estoque }\end{array}$ & $\mathrm{R} \$$ & Custo & $\begin{array}{l}\sum \text { Valor das baixas para alienação de materiais } \\
\text { para estoque }\end{array}$ & Não & 4 áreas \\
\hline 11. & $\begin{array}{l}\text { Índice de sobra } \\
\text { de material por } \\
\text { projeto }\end{array}$ & $\%$ & Custo & $\begin{array}{l}\sum \text { Valor do consumo por projeto / } \sum \text { Valor das } \\
\text { compras por projeto }\end{array}$ & Não & 1 áreas \\
\hline 12. & $\begin{array}{l}\text { Estoque } \\
\text { estratégico }\end{array}$ & $\mathrm{R} \$$ & Custo & $\sum$ Valor do estoque estratégico & Não & 4 áreas \\
\hline
\end{tabular}




\begin{tabular}{|c|c|c|c|c|c|c|}
\hline 13. & $\begin{array}{l}\text { Disponibilidade } \\
\text { dos itens } \\
\text { estratégicos }\end{array}$ & $\%$ & $\begin{array}{l}\text { Nível de } \\
\text { serviço }\end{array}$ & $\begin{array}{l}\sum \text { Qtde de itens estratégicos com estoque / } \sum \\
\text { Qtde de itens estratégicos parametrizados }\end{array}$ & Não & 1 área \\
\hline 14. & $\begin{array}{l}\text { Disponibilidade } \\
\text { dos itens de } \\
\text { ressuprimento } \\
\text { automático }\end{array}$ & $\%$ & $\begin{array}{l}\text { Nível de } \\
\text { serviço }\end{array}$ & $\begin{array}{l}\sum \text { Qtde de itens de ressuprimento automático } \\
\text { com estoque / } \sum \text { Qtde de itens de } \\
\text { ressuprimento automático parametrizados }\end{array}$ & Não & 1 área \\
\hline
\end{tabular}


A seguir é apresentado o detalhamento dos Indicadores descritos na Tabela 1:

1. Estoque total - Somatório do valor (em real) dos materiais e equipamentos em estoque por área. Consiste no valor total empregado em estoque de materiais. Não são incluídos valores referentes a produto acabado, como petróleo e derivados;

2. Estoque de Operação - Somatório do valor (em real) dos materiais e equipamentos em estoque destinado as atividades de operação por área. O Estoque total é divido em duas parcelas, sendo elas: estoque de operação e de investimento;

3. Estoque de Investimento - Somatório do valor (em real) dos materiais e equipamentos em estoque destinado as atividades de investimento por área;

4. Estoque sem consumo há 24 meses - Somatório do valor (em real) dos materiais e equipamentos sem consumo há 24 meses por área. Consiste nos materiais disponíveis em estoque, mas que não apresentam histórico recente de consumo. Podem indicar materiais obsoletos, refletir mudanças de padronização, materiais específicos para projetos cancelados, dentre outros;

5. Estoque destinado a Alienação - Somatório do valor (em real) dos materiais segregados para o processo de alienação/ desmobilização por área. Os materiais sem consumo são anualmente avaliados pelas áreas. Uma vez identificado que não há perspectiva de consumo para o item, o mesmo é destinado ao processo de desmobilização. É importante destacar que manter itens sem expectativa de consumo disponíveis em estoque envolve, além do custo de oportunidade do capital alocado, despesas com armazenagem e movimentação dos itens;

6. Estoque sem previsão de consumo - Somatório do valor (em real) dos materiais em estoque que não possuem previsão de consumo identificado no sistema (sem previsão de uso) por área. São itens disponíveis, mas que não apresentam expectativa de consumo visível no sistema; 
7. Compras recebidas de materiais para estoque - Somatório do valor (em real) das compras recebidas de materiais para estoque por área;

8. Consumo de materiais para estoque - Somatório do valor (em real) do consumo de materiais de estoque por área;

9. Devolução de materiais para estoque - Somatório do valor (em real) da devolução de materiais de estoque por área. São itens que sobraram de aplicações e por esse motivo necessitam retornar ao estoque;

10. Baixa por alienação de materiais para estoque - Somatório do valor (em real) dos materiais alienados/ desmobilizados por área. A baixa por alienação ocorre no momento da entrega do bem para o comprador;

11. Índice de sobra de material por projeto - Somatório do valor (em real) dos materiais comprados para um determinado projeto / Somatório do valor (em real) dos materiais utilizados pelo projeto;

12. Estoque estratégico - Somatório do valor (em real) do estoque parametrizado como estratégico por área;

Obs.: O estoque estratégico é formado por itens de contingência como, por exemplo, sobressalentes.

13. Disponibilidade dos itens estratégicos - Quantidade de itens estratégicos em estoque por área / Quantidade de itens solicitados como estratégico;

14. Disponibilidade dos itens de ressuprimento automático Quantidade de itens de ressuprimento automático por área / Quantidade de itens definidos como estratégico.

Foi identificado na etapa as is que os indicadores não eram comuns a todas as gerências, assim como a métrica de medição e a forma de disponibilização dos dados. Como os indicadores e as métricas utilizadas eram diferentes, não era possível comparar o desempenho das áreas em todas as métricas.

A disponibilização das informações para as áreas envolvidas ocorria de diferentes formas. Algumas gerencias encaminhavam relatórios por e-mail enquanto outras faziam disponibilização em pastas na rede. Um ponto importante a ser considerado é que só existia meta definida para o indicador de Estoques Total. 
Todos os demais indicadores eram acompanhados, mas não tinham ação estruturada ou meta definida o que não se classifica formalmente como uma métrica de desempenho (Braz et al., 2011). Os planos de ação elaborados, muitas vezes, não traziam ações efetivas ou traziam ações que acabavam não sendo acompanhadas de forma efetiva o que dificultava saber se as medidas adotadas estavam surtindo o efeito desejado, o que não está alinhado com a literatura de SMD (Gutierrez et al., 2015). Durante a etapa de entrevistas foi relatado que, apesar do monitoramento de diversos indicadores, não existiam ações estruturadas a serem adotadas em casos de desvios.

Apenas uma gerência monitorava indicadores de nível de serviço como disponibilidade dos materiais, apesar da importância do nível de serviço na operação. O indicador de nível de serviço consiste na disponibilidade dos materiais estratégicos ou de consumo rotineiro. Ou seja, o somatório da quantidade de itens disponíveis em estoque em relação ao total de itens solicitados pelas unidades.

As reuniões de acompanhamento ocorriam de forma descasada com a realidade do momento, ou seja, a análise do desempenho e desvios ocorria muito tempo depois do realizado. Com isso, eram avaliadas situações ultrapassadas e que não faziam mais sentido no cenário atual.

Mesmo com todas as dificuldades apontadas, o cenário as is foi o começo de um SMD e permitiu que fosse instaurada governança sobre o processo. Além disso, houve percepção de ganho de integração entre as áreas que resultou no atingimento da meta.

\section{2}

\section{To Be}

A definição do processo "to be" contemplou a padronização da forma de medição e definição de novo conjunto de indicadores. Foram incluídos indicadores de nível de serviço para todas as áreas.

A seleção dos indicadores para acompanhamento foi feita em função da avaliação quanto a possibilidade de gestão frente a informação apresentada e a relevância da métrica pontuada pelos entrevistados. Indicadores similares foram agrupados. 
O principal ponto levantado pelos gestores, relativo a escolha das métricas para acompanhamento, é que estas precisam, de forma objetiva, mostrar os desvios do processo. Nesse sentido, os indicadores precisam contribuir com a tomada de decisão e ajudar a identificar as etapas em que é necessário agir e de que forma.

Conforme mapeado na literatura, muitos indicadores tendem a gerar problemas quanto a dificuldade de atualização e principalmente de acompanhamento.

Nesse sentido, foram selecionados oito indicadores, conforme apresentado na Tabela 2: 
TABELA 2: Indicadores Revisados

\begin{tabular}{|c|c|c|c|c|}
\hline \multicolumn{2}{|c|}{ Indicador } & \multirow{2}{*}{$\begin{array}{l}\text { Unidade de } \\
\text { Medida } \\
\mathrm{R} \$\end{array}$} & \multirow{2}{*}{\begin{tabular}{|l|} 
Tipo \\
Custo \\
\end{tabular}} & \multirow{2}{*}{$\begin{array}{l}\text { Métrica } \\
\sum \text { Valor dos itens em estoque }\end{array}$} \\
\hline & Estoque Total & & & \\
\hline 2. & Estoque sem consumo há 24 meses & $\mathrm{R} \$$ & Custo & $\sum$ Valor dos itens em estoque sem consumo a 24 meses \\
\hline 3. & Estoque destinado a Alienação & $\mathrm{R} \$$ & Custo & $\sum$ Valor dos itens em estoque em depósito específico de alienação \\
\hline 4. & Estoque sem previsão de consumo & $\mathrm{R} \$$ & Custo & $\sum$ Valor dos itens em estoque sem previsão de consumo \\
\hline 5. & $\begin{array}{l}\text { Índice de sobra de material por } \\
\text { projeto }\end{array}$ & $\%$ & Custo & $\sum$ Valor do consumo por projeto / $\sum$ Valor das compras por projeto \\
\hline & Estoque estratégico & $\mathrm{R} \$$ & Custo & $\sum$ Valor do estoque estratégico \\
\hline 7. & $\begin{array}{l}\text { Disponibilidade dos itens } \\
\text { estratégicos }\end{array}$ & $\%$ & $\begin{array}{l}\text { Nível de } \\
\text { serviço }\end{array}$ & $\begin{array}{l}\sum \text { Qtde de itens estratégicos com estoque / } \sum \text { Qtde de itens } \\
\text { estratégicos parametrizados }\end{array}$ \\
\hline 8. & $\begin{array}{l}\text { Disponibilidade dos itens de } \\
\text { ressuprimento automático }\end{array}$ & $\%$ & $\begin{array}{l}\text { Nível de } \\
\text { serviço }\end{array}$ & $\begin{array}{l}\sum \text { Qtde de itens de ressuprimento automático com estoque / } \sum \text { Qtde } \\
\text { de itens de ressuprimento automático parametrizados }\end{array}$ \\
\hline
\end{tabular}

Fonte: Autora 
Para cada uma das métricas selecionadas para acompanhamento foram definidos: fórmula de cálculo e fonte de coleta dos dados.

De forma geral, as métricas escolhidas têm como objetivo avaliar: se o nível de estoque disponibilizado é o ideal, se existe disponibilidade dos itens solicitados e se os materiais disponíveis estão sendo realmente utilizados e/ou possuem expectativa de consumo.

Após a definição das métricas foi divulgada a nova forma de medição. Nesse momento, as áreas que tiveram seu desempenho piorado com a nova forma de medição acabavam questionando os dados e os novos critérios adotados. Todas as mudanças sugeridas de ajuste foram avaliadas pela gerência de Gestão de Estoques e as aquelas que foram julgadas cabíveis incorporadas as medições. Como a extração de dados ainda estava sendo realizada de forma manual na etapa piloto, esses ajustes puderam ser incorporados com mais facilidade.

A periodicidade mensal de medição foi considerada adequada, apesar dos dados serem extraídos semanalmente para análise e verificação pelos especialistas da área. Foi definido um local comum na rede para disponibilização das bases dos indicadores para análise pelas áreas. A análise semanal dos dados permitiu a ação mais efetiva das ações de monitoramento como, por exemplo, acompanhar devoluções realizadas ao estoque com valor incorreto e realizar os ajustes necessários dentro do mesmo mês.

As reuniões de acompanhamento passaram a ser realizadas a nível de Gerente Executivo, podendo incluir eventualmente gerentes de áreas especialistas. Nesse sentido, mensalmente é realizado reunião de acompanhamento com as áreas envolvidas com o objetivo de avaliar o desempenho e, quando necessário, propor um plano de ação para correção do desvio.

\section{3}

\section{Piloto}

Após a conclusão da etapa de Projeto, teve início a etapa Piloto. Nesse momento, foi operacionalizado o plano para extrair dos bancos de dados existentes as informações, conforme definido anteriormente. Foram ainda determinadas as atividades que seriam necessárias de serem executadas, responsáveis e prazos. 
A etapa piloto teve início em janeiro de 2019 com o objetivo de concluir o ano de 2018 com o mesmo formato de medição que já vinha sendo adotado, possibilitando vínculo com o histórico. Sendo assim, o ano de 2019 começou com os ajustes propostos. O piloto foi realizado no período de janeiro a abril de 2019, tendo duração de quatro meses, após a centralização da área responsável pela Gestão de Estoques de toda a empresa. A seguir são apresentadas as percepções da inciativa sobre diferentes aspectos. Os indicadores estão sendo acompanhados em uma ferramenta desenvolvida em Excel.

Como não houve desenvolvimento sistêmico para a fase piloto, esta contou com muitas extrações manuais, utilizando na maior parte o Excel. Uma das vantagens de não ter havido desenvolvimento sistêmico nessa etapa foi que as métricas de alguns indicadores puderam ser ajustadas de forma mais flexível. Como exemplo, os critérios utilizados para definir estoque sem consumo. Antes o critério levava em consideração apenas o consumo na Unidade que o estoque estava vinculado. Durante o acompanhamento, o critério foi modificado e passou a ser o consumo em toda empresa, considerando a possibilidade de reaproveitar o material em ouras áreas.

$\mathrm{Na}$ etapa piloto foram avaliadas questões importantes como: existência de profissionais qualificados para realizar o acompanhamento; estruturação dos indicadores, operacionalização da coleta dos dados e do processo de análise das informações geradas e tomada de decisão.

Durante a fase de piloto foram analisados ainda os impactos em relação aos catorze motivos que podem levar ao insucesso do processo de desenho e implementação de um SMD, propostos no Capítulo 2. Foram apresentadas ainda ações de mitigação. A síntese da contribuição da etapa piloto será apresentada na sessão 5.3.15.

\subsection{1}

\section{Envolvimento Gerencial}

A iniciativa teve grande envolvimento do corpo gerencial, principalmente no que tange a negociação para definição das metas e a governança de acompanhamento. 
De início, a negociação das metas foi feita a nível operacional. A área de Gestão de Estoques fez a proposta das metas e iniciou a discussão com as áreas operacionais envolvidas, já que o indicador é compartilhado entre ambas as áreas. Como as metas eram desafiadoras, mesmo após dois meses de reuniões e discussões, não houve consenso entre a área de suprimento e as gerências operacionais. Nesse momento, o envolvimento da alta gerência foi fundamental no sentido de validar os números propostos e possibilitar que o acompanhamento fosse iniciado. Enquanto as metas não haviam sido definidas, as reuniões de acompanhamento eram voltadas para o assunto, ao invés da análise do desempenho do processo.

As ações de resistência e desinteresse relatadas na literatura foram percebidas de forma mais significativa na equipe operacional (Kaplan and Norton, 2000; Suwignjo et al., 2000; Holloway, 2001; Kellen, 2003; Bird et al., 2005; Van Camp e Braet 2016). Nesse sentido, em alguns momentos puderam ser identificados desvios de prioridade no acompanhamento.

Uma vez que a alta gerência passou a compartilhar as metas e realizar os acompanhamentos devidos, o trabalho começou a ter visibilidade e ganhar a devida importância. O indicador de estoque total passou a ser incorporado no escopo de remuneração variável. O envolvimento da alta gerência passou então a ser imprescindível no processo de tomada de decisão.

Barreira: A falta de envolvimento gerencial foi pontuada na literatura relacionada a atitudes como: conservadorismo, falta de interesse ou tempo para dedicar a iniciativa, assim como ações de resistência a mudança (Schneiderman, 1999; Bourne et al., 2000, 2002; Kennerley e Neely, 2002; Smith e Goddard, 2002; Scozzi et al., 2005; Garengo et al., 2005; Garengo e Bititci, 2007; Spitzer, 2007; Nudurupati et al., 2011; Kellen, 2003; Van Camp e Braet 2016). Nesse sentido, a barreira identificada na literatura não foi percebida como um significativo obstáculo para a condução do trabalho uma vez que a iniciativa teve apoio da alta administração. Nesse quesito, o ponto de maior dificuldade foi relacionado ao desvio de prioridade durante o acompanhamento que ocorreu em alguns momentos em função da priorização por problemas envolvendo a produção/operação. 


\section{3 .2}

\section{Alinhamento com a Estratégia}

A iniciativa demonstrou total alinhamento com a estratégica organizacional da empresa, fortemente voltada a redução de custos. Estudos internos estimam um custo de $25 \%$ ao ano do valor do material para formação e manutenção do estoque. Ações voltadas a redução de estoques geram redução no capital imobilizado e gastos com armazenagem. A revisão dos indicadores tornou possível avaliar as áreas de forma uniforme e propor ações mais eficazes de melhoria no processo.

Outro ponto importante é que novos indicadores financeiros, que englobam nas métricas o valor do estoque total, como o EVA, passaram a ser adotados pela companhia, o que despertou ainda mais o interesse da alta administração pelo tema. $\mathrm{O}$ indicador é hoje então acompanhado pela área de Estratégia, que realiza a governança de acompanhamento junto a alta administração.

Barreira: A falta de alinhamento com a estratégia foi identificada na literatura como uma dificuldade decorrente do desalinhamento com outras metas da companhia e com a estratégia de longo prazo (Eccles, 1991; Neely, 1999; Schneiderman, 1999; Bourne et al., 2000, 2002; Kellen, 2003; Garengo et al., 2005; Spitzer, 2007; Van Camp e Braet 2016). Essa barreira também não foi um obstáculo para a condução do trabalho uma vez que a estratégia da empresa está fortemente focada na redução de custos o que possibilitou o alinhamento da iniciativa com a estratégia.

\subsection{3}

\section{Procedimento Formal}

Foram definidas fichas dos indicadores contemplando a forma de medição, emitidos padrões e elaborados documentos com o passo a passo orientando a extração dos dados. Como não foi elaborado nenhum documento formal descrevendo a sistemática de governança, muitas dúvidas sugiram sobre o tema. $\mathrm{O}$ ponto foi identificado como uma necessidade de melhoria para as próximas fases. 
Dado o número de áreas envolvidas, a definição de procedimentos é fundamental para que todos possam entender os novos indicadores, métricas e responsáveis.

Barreira: A falta de procedimento formal foi uma barreira identificada na literatura e vivenciada durante a condução do trabalho. Esta é caracterizada pela ausência ou deficiência de documentação e definições formais do processo dificultando a comunicação e definição de responsabilidades (Pawar e Driva, 1999; Schneiderman, 1999; Neely et al., 2000; Bourne et al., 2002; Kellen, 2003; Bird et al., 2005; Scozzi et al., 2005; Garengo e Bititci, 2007; Van Camp e Braet 2016). Apesar de ter sido desenvolvido documentação formal sobre o tema a barreira foi identificada durante o processo de implementação. Foram mapeados lacunas na documentação gerada e necessidade de revisões além de desconhecimento por parte de áreas envolvidas do local onde a documentação estaria disponível.

\section{3 .4}

\section{Frequência na Geração dos Dados}

Como o sistema contempla informação de toda a empresa, o volume de dados extraídos e manipulados foi um dificultador do processo. Havia sido definida uma frequência mensal para o sistema, com periodicidade semanal de extração dos dados para que análises pudessem ser realizadas pelos especialistas da área de Gestão de Estoques. Atualmente dois profissionais dedicam dois dias para extração dos dados e geração dos relatórios.

Em dias próximos ao fechamento do mês, já foi necessário alimentar os indicadores mais de uma vez por semana. Nesse sentido, é necessário o envolvimento da equipe de TI com o objetivo de automatizar a geração das informações.

Barreira: Foi identificada na literatura uma barreira relacionada a frequência insuficiente na geração de dados uma vez que a atualização das métricas com alta frequência pode gerar sobrecarga dos envolvidos na atividade, enquanto a falta de atualização pode fazer da métrica inútil ou defasada com a realidade (Suwignjo et al., 2000; Kennerley e Neely, 2002; Bird et al., 2005; Spitzer, 2007; Cedergren et al., 2010; Hope, 2011; Van Camp e Braet 2016). Esse ponto foi 
identificado como um dificultador na implantação. Para alguns indicadores foi avaliada a necessidade de atualização diária para fins de acompanhamento, fato que só poderá ser proporcionado mediante automatização do processo devido ao esforço de medição. Nesse ponto, a grande dificuldade é achar o ponto ideal no trade off entre os benefícios de poder agir de forma mais rápida frente as variações percebidas e possíveis ajustes e esforço de extrair e analisar as informações geradas.

\subsection{5}

\section{Sistema de Recompensa}

O indicador de Estoque Total foi incluído como meta de desempenho da diretoria, gerentes e demais colaboradores envolvidos. Como o atingimento das metas está vinculado com o sistema de remuneração variável, o sistema de recompensa funcionou de forma adequada.

Uma vez que os demais indicadores refletem no indicador de estoque total, é de interesse dos envolvidos acompanhar todas as métricas e desenvolver ações que possibilitem a redução do estoque alinhada com a garantia das operações, refletida através do nível de serviço.

O indicador "Estoque destinado a Alienação" foi incluído também no scorecard das áreas de armazenagem que são responsáveis pelo processo de alienação dos materiais que não possuem mais expectativa de uso.

A ação de viabilizar sistema de recompensada adequado incentivando a utilização do indicador foi adequado.

Barreira: De acordo com a literatura, a ausência de um sistema de recompensa adequado pode gerar desinteresse pelo processo e ser uma barreira (Hauser e Katz, 1998; Smith e Goddard, 2002; Turban et al., 2011; Van Camp e Braet 2016). A barreira não foi um problema durante a implantação uma vez que foram utilizados sistemas de recompensa atrelados ao pagamento de remuneração variável. A inclusão do indicador como meta de topo da companhia atrelado ao pagamento de remuneração extra, pelo contrário, foi um estímulo para condução dos trabalhos. 


\subsection{6}

\section{Suporte Financeiro}

O sistema não demandou suporte financeiro adicional na etapa piloto de desenvolvimento com TI. Entretanto, irá necessitar em fases posteriores com o intuito de possibilitar automações devido ao esforço de extração de dados.

Durante a etapa piloto foi identificado esforço significativo para extração dos dados e relatórios, por isso, a elaboração de sistema mais automatizado foi incluído nos próximos passos da iniciativa.

Barreira: O processo pode necessitar de gastos adicionais com sistemas, terceirizações, hardware, software, entre outros (Bierbusse e Seisfeld, 1997; Bourne et al., 2002; Garengo et al., 2005; Scozzi et al., 2005; Garengo e Bititci, 2007; Turban et al., 2011; Van Camp e Braet 2016). A barreira foi identificada na condução dos trabalhos uma vez que serão necessários gastos com a automação do processo. Como os gastos não haviam sido previstos no Planejamento Anual da gerência, as melhorias só poderão ser implementadas no próximo ano.

\subsection{7}

\section{Capital Humano}

O sistema demandou dois profissionais designados exclusivamente para extração e atualização dos dados. Alguns colaboradores envolvidos no acompanhamento do processo não tinham o conhecimento necessário sobre o assunto. Com isso, se tornou necessário realizar rodadas de capacitação adicionais as previstas inicialmente.

Com relação a essa ótica foi importante avaliar a existência de pessoas qualificadas para trabalhar com os indicadores. A resposta à questão foi parcialmente, uma vez que foram identificados gaps e a necessidade de melhorar o entendimento dos profissionais sobre o tema.

Barreira: Falta de capital humano, ou seja, ausência das habilidades necessárias para desempenhar as atividades, ou a restrição da quantidade de colaboradores pode trazer impactos na implantação (Pawar e Driva, 1999; Neely et al., 2000; Kennerley e Neely, 2002; Kellen, 2003; Davenport e Harris, 2005; Scozzi et al., 2005; Turban et al., 2011; Van Camp e Braet 2016). A barreira foi vivenciada 
durante a etapa piloto uma vez que foram identificados gaps de conhecimento e necessidade de capacitação sobre o tema. Muitos profissionais designados para acompanhar o SMD eram oriundos de atividades operacionais relativas ao negócio e não tinham conhecimento sobre o tema de Gestão de Estoques o que demandou por parte de equipa de gestão de estoque esforço de disseminar conhecimento sobre o tema, disponibilizando materiais e realizando palestras e treinamentos principalmente com os novos atores.

\subsection{8}

\section{Suporte da TI}

A ausência do envolvimento da área de TI no projeto fez com que a periodicidade da extração dos dados prevista inicialmente (semanal) não pudesse ser mantida. Foi constatada a necessidade de desenvolvimento de uma ferramenta de acompanhamento em ferramenta mais robusta, como o Power BI. A falta de integração com a equipe de TI desde o início de projeto foi um fator crítico que impactou o projeto.

Outra dificuldade identificada nesse sentido foi a qualidade e o tempo de disponibilização das informações. Em alguns meses foram identificadas falhas nos dados disponibilizados pela TI e outros casos, atraso na disponibilização em relação ao cronograma mensal informado.

A aproximação com a área de TI será incluída nos próximos passos do projeto de forma a facilitar a extração dos dados.

Barreira: Falta de suporte da TI pode dificultar a implementação como: integração com sistemas existentes; custos elevados; garantia da qualidade dos dados, dentre outros (Cooper, 1985; Bierbusse e Seisfeld, 1997; Pawar e Driva, 1999; Schneiderman, 1999; Suwignjo et al., 2000; Kuczmarski, 2001; Bourne et al., 2000, 2002; Kellen, 2003; Nudurupati et al., 2011; Van Camp e Braet 2016). A barreira foi identificada uma vez que não foi possível reajustar a frequência de medição das informações conforme desejado devido ao esforço necessário para geração dos dados. Conforme mapeado na literatura, dificuldades com a disponibilidade de dados, dados inexistentes ou não confiáveis são fatores que costumam gerar impacto no prazo de implantação de SMD (Neely e Bourne, 2000; 
Bourne et al., 2002; de Waal \& Counet, 2009; Gutierrez et al., 2015; Mendonça et al., 2019).

\section{3 .9}

\section{Envolvimento do Usuário}

O sistema de recompensas favoreceu o envolvimento dos usuários. No entanto, como as metas estão atreladas a remuneração variável muito tempo foi perdido discutindo metas em reuniões, retardando o início do acompanhamento efetivo dos indicadores. Apesar do incentivo ao envolvimento, foram identificados casos em que a falta de interesse e comprometimento foi um dificultador.

Barreira: A barreira relativa a falta de envolvimento do usuário foi vivenciada durante a etapa piloto. Nesse sentido, foi mapeado na literatura que o não envolvimento dos usuários no desenho e implementação pode gerar modelos complicados, métricas difíceis de medir e falta de interesse/ comprometimento (Kaplan e Norton, 2000; Suwignjo et al., 2000; Holloway, 2001; Kellen, 2003; Bird et al., 2005; Van Camp e Braet 2016);

\subsubsection{0}

\section{Cultura Organizacional}

O SMD de Gestão de Estoques despertou nas áreas operacionais o interesse pelo tema. Como o custo dos materiais e equipamentos só era cobrado das áreas no momento da aplicação, as unidades acabavam não sendo responsabilizadas pelo estoque formado.

A iniciativa fez com que as áreas tivessem maior interesse em usar itens já disponíveis ao invés de solicitar a compra de novos materiais. Foi fomentada ainda a cultura de transferência de materiais sem previsão de uso entre as Unidades. Antes era comum as áreas mesmo sem previsão certa de aplicação não liberar os materiais.

Nesse sentido, a iniciativa teve grande impacto sobre o processo e enfrentou forte resistência devido a cultura organizacional, o que foi um dificultador.

Barreiras: Foram identificados na literatura obstáculos culturais como resistência a mudança, atitudes negativas e conservadoras, falta de vontade/ engajamento (Pawar e Driva, 1999; Bourne et al., 2000; Neely et al., 2000; 
Holloway, 2001; Kennerley e Neely, 2002; Nudurupati et al., 2011; Van Camp e Braet 2016). Os obstáculos relativos a questões culturais mapeados na literatura foram vivenciados durante a condução do trabalho sendo um dos principais dificultadores devido ao grau de resistência gerada.

\subsubsection{1}

\section{Ações Reativas / Pró Ativas}

Existe uma lacuna quanto a identificação de ações pró ativas sobre o tema. Os indicadores são reativos e mostram desvios que ocorreram no passado. A elaboração dos planos de ação e respectivos acompanhamentos são ainda um ponto que requer melhorias uma vez que é difícil saber a quantidade ideal de ações necessários e mensurar o ganho efetivo de cada uma delas.

Barreira: O ponto mapeado na literatura aborda a falta de ações reativas/ pró ativas dificultando a análise do desempenho do SMD (Brouthers, 1998; Pawar e Driva, 1999; Kennerley e Neely, 2002; Smith e Goddard, 2002; Kellen, 2003; Scozzi et al., 2005; Garengo et al.; Andrew et al., 2008; Nudurupati et al., 2011; Van Camp e Braet 2016). Foi identificado durante o projeto dificuldade no desenvolvimento de planos que consigam antecipar problemas futuros. Outro ponto que carece de melhorias é relativo ao acompanhamento dos planos de ação.

\section{3 .12}

\section{Stakeholders}

Apesar do escopo ampliado, englobando toda a companhia, o que acaba gerando maiores desafios, o framework teve boa aceitação. Foram pontuadas particularidades de determinadas áreas durante a etapa piloto, que, em sua grande maioria, puderam ser ajustadas.

Entretanto, como o sistema engloba toda a empresa, a quantidade de áreas envolvidas no processo torna difícil a gestão e o acompanhamento dos planos.

Barreira: Número elevado de stakeholders - O elevado número de partes interessadas envolvidas pode dificultar o processo de tomada de decisão e o consenso entre as partes (Cooper, 1985; Holloway, 2001; Kennerley e Neely, 2002; 
Smith e Goddard, 2002; Scozzi et al., 2005; Franco-Santos et al., 2007; Cedergren et al., 2010; Neely, 1999, 2011; Van Camp e Braet 2016).

\section{3 .13}

\section{Decisões Tomadas pelo Grupo em Detrimento a Decisões Baseadas na Análise dos Dados}

Puderam ser identificados situações em que decisões tomadas pelo grupo não tiveram como base análise de dados, principalmente no que diz respeito ao receio de reduzir a disponibilidade do estoque.

Barreira: Decisões tomadas pelo grupo em detrimento a decisões baseadas na análise dos dados - tomada de decisão subjetiva ao invés de decisões baseadas em métricas e resultados (Schneiderman, 1999; Lazzarotti et al., 2011; Turban et al., 2011; Van Camp e Braet 2016). Nesse sentido, a barreira mapeada na literatura pode ser vivenciada ao longo da condução do trabalho.

\subsubsection{4}

\section{Tempo de Implantação}

A etapa de redesenho teve duração de três meses e a piloto de quatro meses. Não houve atraso em relação previsto, que era começar o ano de 2019 já com as novas métricas. Como o SMD é recente e ainda se encontra na etapa piloto, não foi possível realizar a avaliação quanto capacidade de manter o SMD atualizado frente a inovações e mudanças na organização.

Barreira: Pressão em relação ao tempo - Construir e manter um SMD atualizado requer tempo de desenvolvimento e acompanhamento. A flexibilidade do SMD também é importante para manter a organização atualizada quanto a inovações e mudanças de cenário (Neely, 1998; Kaplan e Norton, 2000; Kellen, 2003; Spitzer, 2007; Chen et al., 2010; Lazzarotti et al., 2011; Van Camp e Braet 2016). A barreira identificada na literatura não foi observada no trabalho uma vez que foram cumpridos os prazos das etapas de Projeto e Piloto. 


\section{3 .15}

\section{Síntese das Contribuições da Etapa Piloto}

Pode ser percebido que a inclusão da etapa piloto possibiltou a mitigação de alguns fatores apresentados mapeados na literatura. A Tabela 3 apresenta uma síntese a análise da inclusão da etapa piloto no que tange a reduzir/ mitigar os riscos mapeados na literatura.

\section{TABELA 3: Barreiras mapeadas e o Projeto Piloto}

\begin{tabular}{|l|l|l|}
\hline$\#$ & Barreiras & $\begin{array}{l}\text { Como a etapa piloto pode ajudar a mitigar/reduzir o } \\
\text { insucesso? }\end{array}$ \\
\hline 1 & $\begin{array}{l}\text { Falta } \\
\text { envolvimento } \\
\text { gerencial }\end{array}$ & $\begin{array}{l}\text { Os gerentes têm a oportunidade de acompanhar de } \\
\text { forma prática os benefícios que a implantação de um } \\
\text { SMD pode proporcionar, facilitando o envolvimento. } \\
\text { Nessa fase eles possuem abertura para propor } \\
\text { melhorias/ajustes no framework que podem ser } \\
\text { implementadas de forma mais imediata }\end{array}$ \\
\hline 2 & $\begin{array}{l}\text { Falta } \\
\text { alinhamento com a } \\
\text { estratégia }\end{array}$ & $\begin{array}{l}\text { Permite verificar se as medições realizadas estão } \\
\text { aderentes com as propostas da estratégia e realizar } \\
\text { eventuais ajustes antes que sejam realizados gastos } \\
\text { com desenvolvimento de softwares, por exemplo }\end{array}$ \\
\hline 3 & $\begin{array}{l}\text { Falta } \\
\text { procedimento } \\
\text { formal }\end{array}$ & $\begin{array}{l}\text { Nesse momento é possível verificar se } \\
\text { procedimentos elaborados na fase de Projeto estão } \\
\text { adequados e realizar eventuais ajustes }\end{array}$ \\
\hline 4 & $\begin{array}{l}\text { Falta de sistema de } \\
\text { recompensa } \\
\text { insuficiente }\end{array}$ & $\begin{array}{l}\text { A etapa piloto permite avaliar a efetividade do sistema } \\
\text { de recompensa frente aos indicadores existentes e, se } \\
\text { necessário, realizar esse ajuste no curto prazo nos } \\
\text { sistemas de recompensa ou no SMD (incluindo ou } \\
\text { retirando indicadores) }\end{array}$ \\
\hline $\begin{array}{l}\text { frequência de medição, avaliando esforço x benefícios } \\
\text { da atualização com maior periodicidade }\end{array}$ \\
\hline
\end{tabular}




\begin{tabular}{|c|c|c|}
\hline 6 & $\begin{array}{l}\text { Falta de suporte } \\
\text { financeiro }\end{array}$ & Não aplica \\
\hline 7 & $\begin{array}{l}\text { Falta de capital } \\
\text { humano }\end{array}$ & $\begin{array}{l}\text { A etapa piloto permite avaliar se o capital humano } \\
\text { disponível está dimensionado de forma adequado e se } \\
\text { foi devidamente treinado }\end{array}$ \\
\hline 8 & $\begin{array}{l}\text { Falta de suporte da } \\
\text { TI }\end{array}$ & $\begin{array}{l}\text { A etapa pode ajudar no sentido de evitar } \\
\text { desenvolvimentos desnecessários para fase de } \\
\text { implantação mas não reduz o suporte necessário da TI }\end{array}$ \\
\hline 9 & $\begin{array}{ll}\text { Falta } & \text { de } \\
\text { envolvimento do } & \text { do } \\
\text { usuário } & \end{array}$ & $\begin{array}{l}\text { Os usuários têm a oportunidade de acompanhar de } \\
\text { forma prática os benefícios que a implantação de um } \\
\text { SMD pode proporcionar, facilitando o envolvimento. } \\
\text { Nessa fase eles possuem abertura para propor } \\
\text { melhorias/ajustes no framework que podem ser } \\
\text { implementadas de forma mais imediata }\end{array}$ \\
\hline 10 & $\begin{array}{l}\text { Obstáculos } \\
\text { Culturais }\end{array}$ & Não aplica \\
\hline 11 & $\begin{array}{l}\text { Falta de ações } \\
\text { reativas/ pró ativas }\end{array}$ & Não aplica \\
\hline 12 & $\begin{array}{l}\text { Número elevado de } \\
\text { stakeholders } \\
\text { envolvidos }\end{array}$ & Não aplica \\
\hline 13 & $\begin{array}{l}\text { Decisões tomadas } \\
\text { pelo grupo em } \\
\text { detrimento a } \\
\text { decisões baseadas } \\
\text { na análise dos } \\
\text { dados }\end{array}$ & $\begin{array}{l}\text { A etapa piloto tem como objetivo avaliar a efetividade } \\
\text { do SMD proposto no auxílio a tomada de decisão }\end{array}$ \\
\hline 14 & $\begin{array}{l}\text { Pressão em relação } \\
\text { ao tempo }\end{array}$ & $\begin{array}{l}\text { Essa etapa pode ainda alargar o tempo de } \\
\text { implementação }\end{array}$ \\
\hline
\end{tabular}

Fonte: Autora

Não foram mapeados benefícios adicionais com a inclusão da etapa piloto para as seguintes barreiras: falta de suporte financeiro, obstáculos culturais, falta de ações reativas/ pró ativas, número elevado de stakeholders envolvidos. 


\section{4}

\section{Road Map}

O Road Map previsto na Tabela 4 aborda as próximas etapas para melhoria do SMD e o cronograma macro previsto para implementação em função dos meses. As atividades número 1 e 2 consistem em contatar a área de TI para automatizar a extração dos dados e possibilitar a utilização de ferramenta mais robusta e dinâmica. É esperado que o acompanhamento, hoje realizado em Excel, possa ser migrado para outro sistema que possibilite gerar as informações de forma mais rápida e eficiente. Nesse sentido, foi proposta a utilização do software Power BI, indicado para manusear grande quantidade de dados.

A atividade 3 consiste em viabilizar que o indicador "Sobra de Paradas" possa ser medido para todas as áreas. Esta etapa demanda mais tempo uma vez que engloba a necessidade de revisão de processos existentes. Para que seja possível medir o indicador "Sobra de Paradas" é importante que o processo de solicitação de material de algumas áreas seja revisado. A atividade 4 consiste em uma primeira revisão de SMD, conforme preconizado em Gutierrez et al. (2015). Nesse momento deverá ser realizada uma avaliação do processo e identificados pontos de melhorias e com necessidade de revisão.

\section{TABELA 4: Cronograma de Implementação (em meses)}

\begin{tabular}{|c|c|c|c|c|c|c|c|c|c|c|c|}
\hline Atividade & 1 & 2 & 3 & 4 & 5 & 6 & 7 & 8 & 9 & 10 & 11 \\
\hline 1- Automatizar extração dos dados & & & & & & & & & & & \\
\hline $\begin{array}{l}\text { 2-Migrar ferramenta de } \\
\text { acompanhamento do Excel para o } \\
\text { Power BI }\end{array}$ & & & & & & & & & & & \\
\hline $\begin{array}{l}\text { 3-Alinhar métrica e processos do } \\
\text { indicador "Sobra de Paradas" para } \\
\text { que seja possível mensurar todas as } \\
\text { áreas }\end{array}$ & & & & & & & & & & & \\
\hline 4 - Revisão do SMD & & & & & & & & & & & \\
\hline
\end{tabular}

Fonte: Autora 


\section{6. \\ Conclusões}

De acordo com Fernandez et al. (2012), o desempenho de uma organização deve ser medido através de valores quantificáveis e classificáveis com o objetivo de subsidiar a tomada decisão dos gestores (Fernandez et al., 2012). Segundo Neely et al. (1995), a medida de desempenho é uma métrica usada para quantificar ações passadas tornando possível a comparação com objetivos estabelecidos. Apesar da reconhecida importância do tema, os estudos identificados são, em sua grande maioria, orientados no desenho de novos sistemas, sendo poucos destinados a análise da implementação e atualização contínua dos sistemas (Borne et al.,2000; Gutierrez et al., 2015; Van Camp e Braet, 2016).

De acordo com Goshu e Kitaw (2017), a literatura referente a SMD ainda não possui consenso em relação a quais são as condições necessárias e suficientes para que um sistema obtenha sucesso ou ainda quais os fatores que devem suportar sua elaboração. Van Camp e Braet (2016) destacam o fato de não ser incorporado aos frameworks existentes falhas encontradas durante a implantação em sistemas reais com o objetivo de aprimorar os modelos.

O trabalho desenvolvido utilizou a metodologia "Discovery Oriented Approach" de Menon et al. (1999), contemplando três dimensões: teórica, industrial/prática e estudo de caso. A visão teórica teve o objetivo de avaliar os conceitos de SMD já disponíveis na literatura e identificar gaps que pudessem gerar pesquisas futuras. A revisão da literatura foi realizada conforme proposta por Cauchick (2007), de forma não sistemática. Nessa etapa, foram mapeados os principais conceitos relativos ao tema, estudos, frameworks, dificuldades enfrentadas durante a implantação/ revisão de SMD e como a inclusão da etapa piloto pode auxiliar no processo de implantações. A terceira etapa consistiu no estudo de caso.

Após mapeamento das principais causas de insucesso dos sistemas de medição, o trabalho propôs uma adaptação da sistemática proposta por Bourne et al. (2000) que prevê as etapas: projeto, implementação e uso/revisão, incluindo a 
etapa piloto, anterior a fase de implementação. A etapa piloto aparece na literatura como uma alternativa para contribuir na mitigação de problemas identificados na fase de implementação, sendo bastante comum em estudos da área de tecnologia de informação (Alles et al., 2018).

$\mathrm{Na}$ dimensão industrial/prática, foram abordados profissionais de uma empresa do setor de óleo e gás com o objetivo de avaliar a adequação do modelo proposto. O estudo empírico foi realizado na mesma empresa, na área de Gestão de Estoques. Nesse sentido, foi realizada a etapa de Projeto e, na sequência, a etapa Piloto, tendo duração de três e quatro meses respectivamente.

Foi percebido que a inclusão da etapa Piloto pode auxiliar na mitigação ou redução dos riscos mapeados na revisão da literatura no sentido que a etapa permitiu maior flexibilidade na realização de adaptações em comparação ao modelo previsto inicialmente.

Das catorze barreiras identificados na revisão bibliográfica, oito foram mapeadas como um problema vivenciado na fase de implantação, sendo elas:

1. Falta de procedimento formal;

2. Frequência insuficiente;

3. Falta de suporte da TI;

4. Falta de envolvimento do usuário;

5. Obstáculos Culturais;

6. Falta de ações reativas/ pró ativas;

7. Número elevado de stakeholders;

8. Decisões tomadas pelo grupo em detrimento a decisões baseadas na análise dos dados.

Dentre as barreiras vivenciadas, as que tiveram maior impacto durante a etapa piloto foram aquelas relativas aos obstáculos culturais e o número elevado de stakeholders envolvidos. Ações de redução de estoques pressupõe orientação voltada a redução de custos e as áreas operacionais estavam historicamente orientadas a maximização da produção e pouco controle de custo. O número elevado de stakeholders foi um dificultador significativo uma vez que o controle foi estendido a Unidades operacionais com realidades bastante diferentes. 
Seis barreiras não foram evidenciadas até o presente momento de forma significativa ou que pudessem causar impacto no desenvolvimento do trabalho, sendo elas:

1. Falta de envolvimento gerencial;

2. Falta de alinhamento com a estratégia;

3. Falta de sistema de recompensa;

4. Falta de suporte financeiro;

5. Falta de capital humano;

6. Pressão em relação ao tempo.

Apesar das barreiras identificadas, o trabalho obteve sucesso ao aprimorar o SMD referente a Gestão de Estoque, na medida que foram uniformizadas métricas, definidas metas, desenvolvidos procedimentos formais e estabelecida sistemática de acompanhamento e gestão sobre o processo. O sistema desenvolvido possibilitou comparar diferentes áreas e identificar ações que possibilitassem otimizar o estoque da companhia.

Como sugestão para pesquisas futuras, pode ser destacada a utilização da etapa piloto em outros processos de implantação/ revisão de SMDs de forma a analisar sua contribuição ao processo (desenvolver). É interessante ainda trabalhar com pesquisas que possibilitem o mapeamento de causas adicionais de insucesso e possiveis ações de mitigação. 


\section{7}

\section{Referências Bibliográficas}

ALLES, Michael et al. (2006). Continuous monitoring of business process controls: A pilot implementation of a continuous auditing system at Siemens. International Journal of Accounting Information Systems, v. 7, n. 2, p. 137-161.

ANDREW, J., HAANAES, K., MICHAEL, D., SIRKIN, H. e TAYLOR, A. (2008). "A BCG senior management survey", Measuring Innovation 2008: Squandered Opportunities, Boston ConsultingGroup, Boston, MA, p. 1-21.

BIERBUSSE, P. e SIESFELD, T. (1997). "Measures that matter". Journal of Strategic Performance Measurement, v. 1, p. 6-11.

BIRD, S.M., COX, D., FAREWELL, V., GOLDSTEIN, H., HOLT, T. e SMITH, P. (2005). "Performance indicators: good, bad, and ugly", Journal of the Royal Statistics Society, s. A, v.168, n.1, p. 1-27.

BOURNE, M., MILlS, J., WILCOX, M, NEELY, A. e PLATTS, K. (2000). "Designing, Implementing and Updating Performance Measurement Systems". International Journal of Operations \& production Management, v.20, n.7, p.754771.

BOURNE, M., NEELY, A., PLATTS, K. e MILLS, J. (2002). "The success and failure of performance measurement initiatives. International Journal of Operations \& Production Management”, v. 22, n. 11, p. 1288-1310.

BOURNE, M.; NEELY, A.; MILLS, J.; PLATTS, K. (2003). Implementing performance measurement systems: a literature review. International Journal of Business Performance Management, v. 5, n.1, p. 1-24.

BOURNE, M., FRANCO-SANTOS, M., MICHELI, P. e PAVLOV, A. (2018). "Performance measurement and management: a system of systems perspective. International Journal of Production Research”, v. 56, n. 8, p. 2788-2799. 
BRAZ, R.G.F., SCAVARDA, L.F. e MARTINS, R.A. (2011). "Reviewing and improving performance measurement systems: an action research". International Journal of Production Economics, v.133, p. 751-760.

BROUTHERS, K., ANDRIESSEN, F. e NICOLAES, I. (1998). "Driving blind: strategic decision-making in small companies”. Long Range Planning, n. 31, p.130 138.

CAUCHICK-MIGUEL, P. A. (2007). Estudo de caso na engenharia de produção: estrutura e recomendações para a sua condução. Produção, 17 (1), 216-229.

CEDERGREN, S., WALL, A. e NORSTRÖM, C. (2010). "Evaluation of performance in a product development context", Business Horizons, v.53, n.4, p.359-369.

CHEN, Y.M., GOAN, M. e CHENG, P. (2010). "Uncertainty and risk analysis in information system projects development”, Journal of Uncertain Systems, v.4, n.1, p.34-46.

COOPER, R.G. (1985). "Selecting winning new product projects", Journal of Product Innovation Management, v.2, n.1, p.34-44.

DAVENPORT, T.H. e HARRIS, J.G. (2005). “Automated decision making comes of age", MIT Sloan Management Review, v.46, n.4, p.82-90.

DE WAAL, A. A. e COUNET, H. (2009). "Lessons learned from performance management systems implementations". International Journal of Productivity and Performance Management, v. 58, n. 4, p. 367-390.

DIXON, J. R., NANNI, A. J., e VOLLMANN, T. E. (1990). “The new performance challenge: measuring manufacturing for world class competition". Dow JonesIrwin, Homewood, IL. 
ECCLES, R. (1991). "The performance measurement manifesto". Harvard Business Review, p.131- 137.

ERIK ERIKSSON, Per. (2010). "Improving construction supply chain collaboration and performance: a lean construction pilot project”. Supply Chain Management: An International Journal, v. 15, n. 5, p. 394-403.

FERNANDEZ, N. S., SCAVARDA, L.F, LEIRAS, A. e HAMACHER, S. (2012). "Diseño de Sistemas de medición de desempeño de provedores: experiências de um caso de estúdio". Produção, v.22, n.1, p. 43-57.

FOSSO W., S. e TAKEOKA C., A. (2010). "The impact of RFID technology on warehouse process innovation: A pilot project in the TPL industry". Information Systems Frontiers, v.13, n.5, p. 693-706.

FORZA, Cipriano. (2002). Survey research in operations management: a processbased perspective. International journal of operations \& production management, v. 22 , n. 2 , p. $152-194$.

FRANCO-SANTOS, M., KENNERLEY, M., MICHELI, P., MARTINEZ, V., MASON, S., MARR, B., GRAY, D. e NEELY, A. (2007). “Towards A Definition Of A Business Performance Measurement System”. International Journal Of Operations \& Production Management, v. 27, n. 8, p. 784-801.

FRANCO-SANTOS, M. e BOURNE, M. (2005). An examination of the literature relating to issues affecting how companies manage through measures. Production Planning and Control, v. 16, n. 2, p. 114-124.

GARENGO, P., BIAZZO, S. e BITITCI, U.S. (2005). "Performance measurement systems in SMEs: a review for a research agenda", International Journal of Management Reviews, v. 7, n. 1, p. 25-47. 
GARENGO, P. e BITITCI, U. (2007). "Towards a contingency approach to performance measurement: an empirical study in Scottish SMEs", International Journal of Operations \& Production Management, v. 27, n. 8, p. 802-825.

GOSHU, Y.Y. e KITAW, D. (2017). "Performance measurement and its recent challenge: a literature review". International Journal Business Performance Management, v.18, n. 4, p. 381-402.

GUTIERREZ, D. M., SCAVARDA, L. F., FLORENCIO, L. e MARTINS, R.A. (2015). "Evolution of the Performance Measurement System in the Logistics Departament of a broadcasting company: An action research". International Journal of Production Economics, v.160, p. 1-12.

HAYES, R. H. e GARVIN, D. A. (1982). "Managing as if tomorrow mattered". Harvard Business Review, v. 60, n. 3, p. 70-79.

HAUSER, J. e KATZ, G. (1998). “Metrics: you are what you measure!”, European Management Journal, v. 16, n. 5, p. 517-528.

HOLLOWAY, J. (2001). "Investigating the impact of performance measurement", International Journal of Business Performance Measurement, v. 3 n. 2-4, p. 167180.

HOPE, J. (2011). "Budgeting to the adaptive organization", in Neely, A. (Ed.), Performance Measurement - Theory and Practice, Cambridge University Press, Cambridge, p. 163-178.

HOURNEAUX Jr., F., CARNEIRO-DA-CUNHA, J. A. e CORRÊA, H. L. (2017). "Performance Measurement and Management Systems: Different Usages in Brazilian Manufacturing Companies”. Managerial Auditing Journal, v. 32, n. 2, p. 148-166.

KAPLAN, R. S. e NORTON, D. P. (1996). "The balanced scorecard: translating strategy into action”. Harvard Business Press. 
KAPLAN, R. e NORTON, D. (2000). “The Strategy-focused Organization: How Balanced Scorecard Companies Thrive in the New Business Environment", Harvard Business Review Press, Boston, MA.

KEATHLEY, H. e VAN AKEN E. M. (2013). "Systematic literature review on the factors that affect performance measurement system implementation". IIE Annual Conference and Expo 2013, p. 837-846.

KEEGAN, D.P., EILER, R.G. e JONES, C.R. (1989). “Are your performance measures obsolete?", Management Accounting, pp. 45-50.

KELLEN, V. (2003). "Business performance measurement: at the crossroads of strategy, decision making, learning and information visualization", working paper, DePaul University, Chicago, IL, February.

KENNERLEY, M. e NEELY, A. (2002). "A framework of the factors affecting the evolution of performance measurement systems", International Journal of Operations \& Production Management, v. 2, n. 11, p. 1222-1245.

KUCZMARSKI, T. (2001). "Five fatal flaws of innovation metrics", Marketing Management, v. 10. n. 1, p. 34-39.

LAZZAROTTI, V., MANZINI, R. e MARI, L. (2011). "A model for R\&D performance measurement", International Journal of Production Economics, v. 134 n. 1, p. 212-223.

LIU, Yi et al. (2016). "An Internet-of-Things solution for food safety and quality control: A pilot project in China". Journal of Industrial Information Integration, v. 3, p. 1-7.

LYNCH, R. L. e CROSS, K. F. (1991). "Measure Up! The Essential Guide to Measuring Business Performance”. Mandarin, Londres, p. 213. 
LOHMAN, C., FORTUIN, L. e WOUTERS, M. (2004). “Designing a performance measurement system: A case study". European Journal of Operational Research, v. 156, n. 2, p. 267-286.

MENDONCA, P. R. C. (2019). "Fatores Críticos de Sucesso dos Sistemas de Medição de Desempenho - Estudo de Caso de Diferentes Iniciativas Aplicadas em Uma Única Empresa”. Rio de Janeiro, 2019. Dissertação (mestrado) - Pontifícia Universidade Católica do Rio de Janeiro.

MENON, A., BHARADWAI, S.G., ADIDAM, P.T. e EDILSON, S.W. (1999). “Antecedents and Consequences of Marketing Strategy Making: A Modeland a Text”, Journal of Marketing, v. 63, n. 2, p. 18-40.

MEREDITH, J. (1993). "Theory building through conceptual methods”. International Journal of Operations \& Production Management, v. 13, n. 5, p. 3-11.

NEELY, A., GREGORY, M. e PLATTS, K. (1995). "Performance measurement system design: A literature review and a research agenda". International Journal of operations \& Production Management, v.15, n.4, p.80-116.

NEELY, A. , RICHARDS, H., MILLS, J., PLATTS, K. e BOURNE, M. (1997). “Designing performance measures: a structure approach". Cambridge: International Journal of Operations \& Production Management, v. 17, n. 11, p. 1131-1152. 1997.

NEELY, A. (1998). "Measuring Business Performance: Why, What and How." The Economist and Profile Books Ltd, London.

NEELY, A. (1999). "The performance measurement revolution: why now and what next?", International Journal of Operations \& Production Management, v. 19, n. 2, p. 205-228.

NEELY, A. e BOURNE, M. (2000). "Why Measurement Initiatives Fail." Measuring Business Excellence v. 4, n. 4, p. 3-7. 
NEELY, A., MILlS, J., PLATTS, K., RICHARDS, H., GREGORY, M., BOURNE, M. e KENNERLEY, M. (2000). "Performance measurement system design: developing and testing a process-based approach", International Journal of Operations \& Production Management, v. 20 , n. 10, p. 1119-1145.

NEELY, A. (2005). "The evolution of performance measurement research: developments in the last decade and a research agenda for the next", International Journal of Operations \& Production Management, Vol. 25 No. 12, pp. 1264-1277.

NEELY, A. (2011). "Business Performance Measurement: Unifying Theory and Integrating Practice", Cambridge University Press, Cambridge.

NUDURUPATI, S. S., BITITCI, U. S., KUMAR, V. e CHAN, F. T. (2011). "State of the art literature review on performance measurement". Computers \& Industrial Engineering, v. 60, n. 2, p. 279-290.

PAWAR, K.S. e DRIVA, H. (1999). "Performance measurement for product design and development in a manufacturing environment", International Journal of Production Economics, v. 60-61, p. 61-68.

ROCHA, J., SCAVARDA, L.F. e MENDONCA, P. (2020). “A Conceptual Model to Guide the Redesign of Performance Measurement Systems". Operations Management for Social Good, 2018 POMS International Conference in Rio.

RUIZ-GARCIA, L., STEINBERGER, G., e ROTHMUND, M. (2010). “A model and prototype implementation for tracking and tracing agricultural batch products along the food chain". Food Control, v. 21, n. 2, p. 112-121.

SCHNEIDERMAN, A.M. (1999). "Why balanced scorecards fail", Journal of Strategic Performance Measurement, January Special Edition, p. 6-11. 
SCOZZI, B., GARAVELLI, C. e CROWSTON, K. (2005). "Methods for modeling and supporting innovation processes in SMEs", European Journal of Innovation Management, v. 8, n. 1, p. 120-137.

SMITH, P.C. e GODDARD, M. (2002). "Performance management and operational research: a marriage made in heaven?", Journal of the Operational Research Society, v. 53, n. 3, p. 247-255.

SPITZER, D.R. (2007). Transforming Performance Measurement: Rethinking How You and Your Organization Use Measurement, AMACOM, New York, NY.

SUWIGNJO, P., BITITCI, U. e CARRIE, A.S. (2000). "Quantitative models for performance measurement system", International Journal of Production Economics, v. 64, n. 1-3, p. 231-241.

TURBAN, E., SHARDA, R. e DELEN, D. (2011). "Decision Support and Business Intelligence Systems", Pearson, Upper Saddle River, NJ.

VAN CAMP, J. e BRAET, J. (2013). "Proposing a taxonomy for performance measurement systems' failures", University of Antwerpen, working paper n. 2013004

VAN CAMP, J. e BRAET, J. (2016). “Taxonomizing performance measurement systems failures". International Journal of Productivity and Performance Management v. 65, n. 5, p. 672-693.

VOSS, C., Tsikriktsis, N., FROHLICH, M. (2002). Case research in operations management. International Journal of Operations and Production Management. v. 22 n. 2, p. 195-219.

YIN, R. K. (2001). Estudo de caso: planejamento e métodos. trad. Daniel Grassi, 2.ed. Porto Alegre: Bookman. 
Apêndice I:

Questionário para identificar e descrever o atual sistema de medição de desempenho - utilizado para guiar as entrevistas semiestruturadas

Cargo do Entrevistado:

Área de atuação:

Tempo de empresa:

Data da entrevista:

Duração da entrevista:

Relação com o sistema de medição de desempenho:

( ) Envolvido com o desenvolvimento;

( ) Envolvido com a implementação;

( ) Usuário.

1. Quais são as principais medidas de desempenho adotadas na Gestão de Estoques da Petrobras?

2. Para cada medida, por favor, responda as seguintes questões:

3. Quais são os objetivos propostos para a medida de desempenho?

4. Qual é a fórmula de cálculo da medida de desempenho?

5. Quais são as fontes de dados que alimentam as medidas? 
6. Quem é o responsável pela medição?

7. Com que frequência a medição é realizada?

8. Como e quando as metas são reavaliadas?

9. Quem é o responsável pela revisão das metas da medida (valores)?

10. Como e quando as medidas são reavaliadas?

11. Quem é o responsável pela revisão no conjunto de medidas (por exemplo, verificar ou não a necessidade de incluir uma nova medida ou excluir uma antiga)?

12. Quais os principais direcionadores relacionados à medida de desempenho?

13. Como essa métrica contribui para a Gestão de Estoques da Companhia?

14. O conjunto de indicadores adotado é suficiente?

15. Os indicadores são acessíveis/ fáceis de extrair? 
16. Como é o acesso aos dados?

17. Quais as melhorias você acredita que possam ser incorporados ao sistema de medição atual?

18. Como você entende que deve ser o modelo de acompanhamento? 